\title{
Status of ion beam data analysis and simulation software
}

\author{
E. Rauhala $^{1^{*}}$, N. P. Barradas ${ }^{2,3}$, S. Fazinic ${ }^{4}$, M. Mayer ${ }^{5}$, E. Szilágyi ${ }^{6}$, M. Thompson ${ }^{7}$ \\ 1 Accelerator Laboratory, Dept. of Physics, University of Helsinki, P.O. Box 43, FIN-00014 \\ Helsinki, Finland \\ 2 Instituto Tecnológico e Nuclear, Estrada Nacional No. 10, Apartado 21, 2686-953 Sacavém, \\ Portugal \\ 3 Centro de Física Nuclear da Universidade de Lisboa, Av. Prof. Gama Pinto 2, 1649-003 Lisboa, \\ Portugal \\ 4 Rudjer Boskovic Institute, Bijenicka c.54, 10000 Zagreb, Croatia \\ 5 Max-Planck-Institut für Plasmaphysik, EURATOM Association, Boltzmannstr. 2, D-85748 \\ Garching, Germany \\ 6 KFKI Research Institute for Particle and Nuclear Physics, P.O. Box 49, H-1525 Budapest, Hungary \\ 7 Dept. of MS\&E/Bard Hall 328, Cornell University, Ithaca, NY 14853, USA
}

\begin{abstract}
The status of ion beam data analysis codes dedicated to Rutherford backscattering, elastic recoil detection analysis, and non-resonant nuclear reaction analysis, is reviewed. The most important methods and approaches employed are discussed. The stopping power and scattering cross section databases used, the ion-target interaction physics, the experimental and detection system characteristics, and the structure of samples all have a strong impact on the analytical results. The models and algorithms used by different codes are reviewed and discussed in detail. Limitations in existing codes and perspectives for further developments are presented. The importance of ascertaining the correctness and accuracy of different methods and codes used in ion beam data analysis is stressed.
\end{abstract}

PACS: 01.30.R; 07.05.K; 82.80.Yc.

Corresponding author:

Eero Rauhala

Accelerator Laboratory, P.O. Box 64,

00014 University of Helsinki, Finland

Telephone: +358-9-19150011

Fax: +358-9-19150042 
Keywords: Computer software; data analysis; simulation; ion beam analysis; Rutherford backscattering spectrometry; elastic recoil detection

\section{Introduction}

Computer methods in the data analysis of ion beam techniques date back to the 1960's and 1970's. These techniques were developed in parallel with the beginning of the new semiconductor and other high-tech technologies. New needs for ion beams in the production, modification and characterization of novel materials arose in semiconductor and thin film technologies. Ion implantation was established as the most versatile and controllable technique for introducing small amounts of impurities in materials. The superb structural characterization capabilities of ion beams were recognized in the micrometer and submicrometer range. As analysis problems and samples became increasingly complex and detailed, the resulting spectra became too complicated to be treated analytically or with simple computational methods. Concurrently, computers were rapidly developing into standard tools in nuclear physics laboratories, addressing a multitude of computational tasks, including both data analysis and accelerator control. The large mainframe computers of the 60's evolved into the $\mathrm{PC}$ in the 80 's, and to the nearly ubiquitous present in laboratory equipment towards the 2000's.

In this paper, we concentrate on numerical codes dedicated to the Rutherford Backscattering Spectrometry (RBS), Elastic Recoil Detection Analysis (ERDA) and nonresonant Nuclear Reaction Analysis (NRA). These three techniques share characteristics of: (i) incident ions with similar velocities, (ii) a single beam energy, and (iii), detection of a massive particle (e.g. ion or atom). While non-resonant NRA analysis codes are included, we intentionally exclude resonant NRA methods, which scan the incident beam energy. 
Numerous software packages are presently being used by the community for ion beam analysis, including both general purpose tools suitable for one or more techniques and codes dedicated to specific problems or techniques. However, to date no systematic effort has been made to validate these codes, or even to compare results obtained from various codes applied to the same problems. Consequently, ion beam analysis practitioners are forced to use codes whose validity, correctness and accuracy have never been validated beyond the authors' efforts.

The International Atomic Energy Agency (IAEA) previously sponsored intercomparisons of gamma ray analysis software packages ${ }^{1}$, alpha particle spectrometry software packages ${ }^{2}$, and particle induced x-ray emission (PIXE) analysis packages ${ }^{3}$. The present study is based on, and significantly extends, the report ${ }^{4}$ of a technical meeting on the "Status of Software for Ion Beam Analysis in Materials Development", organized by the IAEA in 2002. The IAEA is currently organising a round robin exercise aimed primarily at the intercomparison of RBS, ERDA and non-resonant NRA software packages. Within this endeavor, both theoretical calculations and results of the analysis of experimental data obtained by using various codes will be compared.

We review here the history and current status of ion beam data analysis and simulation software, with particular emphasis on RBS, ERDA and non-resonant NRA techniques. A historical perspective serves to outline the major methods and approaches employed, while also introducing more recent trends and directions. The influence of the fundamental databases required for most packages, particularly stopping powers and cross sections, is discussed. Fundamental physical processes relating to ion-target interaction are discussed within the context of the various computational algorithms and approximations used to model spectra, pointing out known limits of existing approaches. This is followed by a discussion of 
the influence of the measurement system on spectra, and again the approximations and algorithms required to model these effects. Finally, approaches to address sample characteristics, such as roughness, porosity, and crystalline structure, are mentioned. While distinct from issues of simulation validity, methods and algorithms used by codes to automatically or semi-automatically extract elemental concentration depth profiles are also reviewed. Characteristics of 12 ion beam data analysis software packages are presented in Tables 1 through 8 .

\section{History of computer data analysis in ion beam techniques}

This section surveys the historical development of computer based data analysis applied to ion beam techniques. We restricted this discussion charged particle spectra analysis for RBS, ERDA and non-resonant NRA techniques. Codes are divided into five classes roughly following the historical development of the field. Class A) includes programs developed from the early 70's designed to solve specific problems without the explicit potential to analyze the full general case spectrum. Classes B) and C) developed in the 80's and 90's to tackle the complete general case. Class B) encompasses codes that employ direct analysis methods to unfold the spectrum without detailed assumptions of the sample structure. Class C) codes employ indirect methods generally starting from an assumed sample structure and simulating theoretical spectra to be compared with an experimental spectrum. Programs in these two classes are often capable of simulating both RBS and ERDA spectra, and for some NRA spectra. The fourth class D) includes more recent packages with algorithms capable of treating the more complex beam, sample, and experimental interactions and including advanced levels of automation. Many of the currently used software packages fall into this category almost all adopting the theoretical spectra simulation approach. A fifth class E) is 
included for software packages that apply first-principle type simulations of the spectrum development, such as Monte-Carlo approaches.

In each of these classes, only data analysis applications will be considered. For example, simulations of physical processes such as channeling have not been included. It is also realized that no review can be absolutely inclusive, and that many developments in the calculations and formalism of the ion beam data analysis techniques are omitted. This is especially true within Class A where topics considered relevant to later developments and explicit computational and computer references were given preference. Several codes not explicitly included in this section are, however, included in later sections. A literature search ${ }^{5}$ using keywords such as RBS and Rutherford backscattering or ERDA and elastic recoil detection return well over 10000 and 1000 entries, respectively. It is clearly not possible to include all relevant publications and any selection is bound to be subjective. Other short reviews of RBS data analysis software can be found in the literature ${ }^{6,7,8,9}$, and a more extensive survey can be found in a recent article by Jeynes et al. ${ }^{10}$.

Class A)

In 1971, Ziegler and Baglin ${ }^{11}$ published a pioneering article considering, for the first time, computational modeling of many physical phenomena in RBS. The authors describe the principle of slab analysis for the calculation of spectra, divided the sample into thin layers. Scattering kinematics, stopping powers and cross sections were used to obtain ion energies related to the layers and scattering from the layers. A deconvolution calculation was included to correct for the resolution effects and the Optical model was considered in handling nonRutherford cross sections.

Computational modeling of other essential physical effects in ion scattering where explored throughout the early 80's. The origin of the low energy background in 
backscattering spectra due to plural and multiple scattering was studied by Weber and coworkers ${ }^{12,13,14}$ in a computer code DRBS. An analytic formula was developed to predict the background below $1 \mathrm{MeV}$ during proton backscattering, with 20\% accuracy, based on the ion energy, sample thickness and atomic number. The effect of different surface topography ${ }^{15}$ and periodic structures in samples ${ }^{16}$ were studied by Edge and Bill experimentally and by computer calculations based on a statistical model for a variety of surfaces and grating structures, yielding a unique relationship between the energy spectrum and surface parameters for random roughness.

Issues specific to data analysis were also reported extensively starting in the 70's. The fundamental ambiguity of ion beam analysis, the non-unique correspondence between the spectrum and sample, and other issues peculiar to computer data analysis were studied by Rauhala ${ }^{17}$, Alkemade et al. ${ }^{18}$ and Butler ${ }^{19}$. Liau ${ }^{20}$ described a technique to deduce individual signals from overlapped signals in RBS computer simulations by using two slightly different incident ion energies. Problems in extracting accurate depth profiles due to finite detector resolutions in nuclear reaction or RBS spectra were studied by Lewis ${ }^{21}$, using a method combining a Taylor's expansion of the spectrum yield with calculations of convolution integrals. Rickards ${ }^{22}$ pointed out how accurate edge positions and target thicknesses could be extracted from thin sample spectra, which are represented as convolution integrals. O'Connor and Tan ${ }^{23}$, and Yang and coworkers ${ }^{24,25}$ studied especially heavy ion RBS (HIRBS) and developed realistic simulations for heavy ion resolution effects. Vickridge and Amsel ${ }^{26,27}$ described a PC implementation of a stochastic theory for charged-particle energy loss to provide an accurate computational method SPACES for straggling in the simulation of excitation curves during narrow-resonance depth profiling. Hnatowicz et al. ${ }^{28}$ described a non-linear least-squares fitting program RBSFIT where the spectrum is represented as a combination of a variable number of three basic shapes; strip, bulge and 
Gaussian. Independent of the physical nature of the problem, the positions, amplitudes and areas of these basic spectrum components are obtained.

Class B)

The direct spectrum analysis was introduced by Børgesen et al. ${ }^{29}$ with a computer code SQEAKIE to reconstruct the depth profile by closed form analytical calculation from separated signals of the spectrum. This program determined the sample composition as a function of depth by using matrix inversion to solve a set of linear equations for each element at each layer in the sample. This approach can be straightforward and effective in many cases. However, problems arise with, for example, the implementation of straggling and the stability of results due to uncertainties in the stopping database and measurement noise. This program has been used as a reference against later computer programs. For the case of two overlapping signals from a binary compound, iterative deconvolution procedures starting from the surface were suggested. Petrov et al. ${ }^{30}$ examined computer analysis of spectra from binary compound films and showed how the lighter element signal could be omitted in the calculation. A SQEAKIE - like analysis routine was extended to an automatic iterative fitting code (BASF backscattering spectrum fitter) for samples with up to five elements by Eridon and Was ${ }^{31}$. Other programs utilizing similar direct approaches have also been reported ${ }^{32,33}$. Zhang et al. 34 studied the deconvolution of RBS spectra for binary mixtures using Fourier transform techniques. Edge ${ }^{35}$ reported an iterative technique for depth profiling based on spectra taken at different angles. Michaelian and Andrade ${ }^{36}$ presented a direct procedure for homogeneous multielemental samples. A more general matrix inversion code, BEAM EXPERT (see Tables $1-8)$, was released by Kogan et al. ${ }^{37}$. 
Class C)

In 1976 Ziegler and co-workers ${ }^{38,39,40}$ published the first full simulation program code IBA (see Tables $1-8$ ) utilizing the indirect method. The principle of calculations was the same as earlier described by Ziegler and Baglin. Beginning from a hypothetical sample structure, the corresponding theoretical RBS energy spectrum was simulated. This was accomplished by dividing the sample into slabs or slices in depth (see also for example ${ }^{41}$ ), chosen sufficiently thin to render energy loss and cross section changes negligible within any slice. Tables of energies on the ion inward and outward paths were calculated from known stopping cross sections, with separate tables for scattering from every target atom species in every slice maintained on the outward path. The total scattering contributions from all slices where then convoluted with the detection system resolution to produce a final theoretical spectrum. Experimental and theoretical spectra were compared, followed by a few userinitiated iterations of the sample composition, until sufficient overlap was achieved. The hypothetical sample structure was then taken to correspond to the real sample structure. In addition to this general computational principle, detailed interactions could be readily incorporated in various stages of calculations.

In 1978 Müller and coworkers ${ }^{42}$ studied proton and heavy ion backscattering spectrum data analysis using a similar simulation program. The stopping of heavy ions was extracted by using polynomials from the tabulations of Northcliffe and Schilling ${ }^{43}$. Rapid changes of composition vs. depth were examined. Careful handling of isotopes and detector resolution effects was found to be important for simulation heavy ions spectra.

Throughout the 80 's, several similar simulation codes were developed. Marcuso et al. ${ }^{44}$ reported a program DAP (Deuterium Analysis Program) for analysis of $\mathrm{D}\left({ }^{3} \mathrm{He}, \alpha\right) \mathrm{H}$ reaction measurements. The program used reaction kinematics, Bragg's Rule for stopping cross section additivity, and experimental reaction cross sections to produce an $\alpha$-yield energy 
spectrum which could be compared with experimental data. The DAP algorithm treated effects such as angular divergence and angular spread of ions, geometric effects, and Bohr straggling finite detector resolution in the final convoluted $\alpha$-spectrum.

Rauhala ${ }^{45}$ introduced automatic iterations in RBS data analysis through a full simulation procedure where parameters (signal heights, widths, areas, etc.) from an experimental spectrum were used as input. The code automatically iterated the simulations, rapidly converging to a theoretical spectrum exactly reproducing the input parameters, and yielding a final analysis of the sample.

Simpson and Earwaker ${ }^{46,47}$ extended the deuterium nuclear reaction data analysis to handle arbitrary reactions.

Kido and Oso ${ }^{48}$ described three types of computer simulation codes for the analysis of random and channeled RBS spectra: multielemental, multilayered structures, specimens with inhomogeneous distribution of impurities and single crystals damaged by ion implantation. Surface and interface roughness effects were also discussed.

Doolittle ${ }^{49,50}$ reported of a simulation program RUMP (see Tables $1-8$ ) used in Cornell University, which was optimized for small computers. This program later became the first widely used RBS (and later also ERDA) data analysis software for PC's. The code optimized performance by using approximations to the stopping powers and scattering cross sections integrals across thick slabs, retaining fine structure only in regions of varying compositions. The code also introduced an automated sample structure parameter search (PERT) with quantitative estimation of uncertainties. Other authors have published extensions to the program, e.g., Knox et al. ${ }^{51}$ - fits of non-Rutherford cross sections included in RUMP - and studies of stopping cross sections adopted in RUMP by Climent-Font et al. ${ }^{52}$. 
Butler described a desktop computer program ${ }^{53}$ and an automatic display ${ }^{54}$ for simulating energy spectra of He ions scattering into two concurrent detectors, one at the backward and one at the glancing angle geometry.

Computer data analysis of proton backscattering with an emphasis on non-Rutherford scattering cross sections was studied by Rauhala ${ }^{55}$.

In the subsequent decade, numerous additional codes have been developed with ever increasing versatility 56,57,58,59,60,61,62,63,64,65,66,67. All ions, both RBS and ERDA, nonRutherford cross sections, plural and multiple scattering, finer details, such as corrections for basic screening and straggling, detector response, etc. have been incorporated. Some of these codes were also capable of automatic or semiautomatic iterations.

Vizkelethy reported a simulation program SENRAS for RBS, ERDA and NRA spectrum analysis. Any ion-target combination could be treated, with stopping powers based on the $\mathrm{ZBL}^{68}$ formalism and cross sections taken from experimental data.

More specific applications were studied by Guo et al. . They investigated the simulation of RBS spectra for laterally inhomogeneous sample structures, semiconductor device edge and sidewall structures, reporting a program for treating RBS data from three-layer stripe structures representing features of a three dimensional semiconductor integrated circuit.

The simulation approach by Serryus et al. ${ }^{58,59,60}$ introduced a "retrograde" method in a code PERM (see Tables $1-8$ ), where the ions on the outward path are followed in a "time reversed" direction: ions recorded at the detector are assumed to penetrate back into the sample with an increasing energy in the sample. This method is more effecient as stopping powers need to be computed only once for each element (isotope) in the sample.

Saarilahti and Rauhala modified and extended the earlier software to include effective and extensive calculations fully utilizing the PC environment in a code GISA (see Tables 1 - 
8). Examples were shown for ion backscattering data analysis for $12 \mathrm{MeV}{ }^{12} \mathrm{C}$ ions incident on an $\mathrm{YBa}_{2} \mathrm{Cu}_{3} \mathrm{O}_{7}$ superconductor and $4.3 \mathrm{MeV}{ }^{4} \mathrm{He}$ ions on a SrS film with non-Rutherford contributions from $\mathrm{O}$ and $\mathrm{C}$.

Skelland's software package BAS has special features for the analysis of charging effects in RBS spectra from insulators.

The DVBS code (see Tables $1-8$ ) developed by Boháč and Shirokov incorporated a menu-driven interface with powerful capabilities to change automatically the concentration of a given element in a given element based on the difference between data and simulation in the corresponding energy range.

An interactive simulation software package RBX (see Tables $1-8$ ) was published by Kótai ${ }^{9}$ in 1994. This package, which can perform automatic iterations, is versatile, general and widely distributed.

The simulation code BSCAT by Rachel was created to deal with the RBS and NRA data analysis of multielemental and multilayer samples prepared by the ion beam assisted deposition.

Nishimura and coworkers ${ }^{69}$ introduced nuclear model calculations of scattering cross sections in connection with a simulation code. By performing a partial wave phase-shift analysis and describing the ${ }^{16} \mathrm{O}(\mathrm{He}, \mathrm{He}){ }^{16} \mathrm{O}$ resonance at $3.045 \mathrm{MeV}$ by a single-level BreitWiegner formula, the authors implemented the cross sections in the simulations as a twodimensional matrix of energy and scattering angle from $2.0 \mathrm{MeV}$ to $3.2 \mathrm{MeV}$ and from $70^{\circ}$ to $178^{\circ}$. Examples of $\mathrm{YBa}_{2} \mathrm{Cu}_{3} \mathrm{O}_{8}$ and $\mathrm{Nd}_{1+\mathrm{x}} \mathrm{Ba}_{2-\mathrm{x}} \mathrm{Cu}_{3} \mathrm{O}_{7-\delta}$ spectrum analysis were presented.

\section{Class D)}


By the end of the 1990's, simulation and ion beam analysis programs had developed in a multitude of directions. Several codes handling very general data analysis problems and various ion beam analysis techniques like RBS, ERDA, NRA etc. were, and are, in common use. Many were highly automatic, while others focused on addressing specified problems with precision and completeness, such as in Marin et al. ${ }^{70}$ Kótai ${ }^{71}$, Weller (code Particle Solid Tools, see Tables $1-8)^{72}$, and Stoquert and Szörényi ${ }^{73}$. The most recent software developments have evolved to incorporate many of the specific refinements into general codes coupled with automated spectrum evaluation and sample structure determination.

In 1997, a computer program WiNDF (see Tables $1-8)^{74,75}$, capable of extracting the depth profiles of elements in samples by automatic iterations without any user interference, was presented by Barradas and coworkers. The code marked a significant departure from existing packages by using a simulated annealing algorithm ${ }^{76,77}$, requiring the user only to input the data to be analyzed, the experimental conditions and the elements present. The analysis of several spectra from different techniques such as RBS, ERDA, etc. could be handled simultaneously and interrelated. This code is general, not optimized for any given system. In 2000, Barradas and Vieira introduced a new artificial neural network (ANN) algorithm approach ${ }^{78}$. This algorithm is optimized for a given system rendering instant analysis of large batches of similar samples. More than 30 articles have been published on WiNDF and ANN or their application to ion beam analysis, see references of .

Another general software package SIMNRA (see Tables $1-8$ ) for RBS, ERDA and NRA data analysis was introduced by Mayer in $1997^{79,80,81}$. The program, with a fully graphical interface, handles all ion-target combinations in any geometry including transmission with a capability of dual scattering calculation. It also contains an extensive database of more than 300 non-Rutherford scattering and nuclear reaction cross sections. 
Tosaki and coworkers ${ }^{82}$ considered the influence of energy straggling for rapidly changing cross-sections in a code BS1 (see Tables $1-8$ ), for instance around a sharp resonance, and showed that the peak profile due to a sharp resonance is very sensitive to the degree of energy straggling.

Many of the RBS data analysis programs referred to in C) included the ability to simulate also ERDA and NRA spectra measured with the conventional Si-charged particle detector. ERDA spectrometry has recently shifted to using additional specific detection systems, such as time-of-flight (TOF) or gas ionization detectors. Analysis of spectra taken with such systems is more dependent on the experimental technique and apparatus, and similar general data analysis software, as in the case of RBS, do not yet exist and may not be feasible. Software for ERDA are thus usually tailored to solve a variety of specific data analysis problems, such as the channel-depth conversion ${ }^{83,84,85,86,87,88,89,90}$ or to study surface roughness effects ${ }^{91,92}$. Extensive studies based on analytical calculations on the effects of energy-spread phenomena and multiple scattering in the depth resolutions (the DEPTH code, see Tables $1-8)^{93,94}$, and in ERDA data analysis have been published by Szilágyi ${ }^{95}$ and Wielunski et al. ${ }^{96}$. Heavy ion ERDA with magnetic spectrometers is often used to achieve very good depth resolution, even atomic resolution, near to the surface ${ }^{97}$. Simulations taking into account the main energy spread effects for high-energy resolution HI-ERDA measurements have been performed. To extend the analytical calculations, many recent approaches for treating ERDA utilize Monte Carlo techniques.

\section{Class E)}

In addition to computational techniques intended for data analysis, other methods are also widely used in ion beam physics. First principles methods, primarily Monte Carlo and Molecular Dynamics calculations, are increasingly being used to study physical processes 
taking place in lower energy interactions, such as ion implantation. The most recent codes are also capable of simulating the higher energy processes relevant for ion beam analysis, using high performance computer systems to obtain results in reasonable time. These include, e.g., Monte Carlo treatment of multiple scattering, rough targets, ion transport through time-offlight detector systems etc. Such computational techniques are rapidly approaching a stage where they could be incorporated in real time data analysis calculations.

Monte Carlo calculations have been used for example to evaluate the effects of surface roughness in RBS by Shorin and Soshin ${ }^{98}$ and multiple and plural scattering in RBS spectra by Bauer, Biersack and Steinbauer ${ }^{99,100,101}$, Li and O’Connor ${ }^{102}$, Eckstein and Mayer ${ }^{103}$, Pusa et al. ${ }^{104}$; and in heavy ion ERDA spectra by Sajavaara, Arstila and coworkers ${ }^{105,106}$ and Franich, Johnston and coworkers. ${ }^{107,108}$.

\section{Fundamental databases}

The validity of ion beam data analysis is ultimately linked to a few physical processes and to a small number of critical databases. ${ }^{109}$. Fundamentals include understanding of the energy transfer between energetic particles and the sample, commonly treated as a stopping power cross section, and the strength of the nuclear interactions or scattering cross sections. The accuracy of any simulation software is hence critically dependent on the accuracy of the underlying models and/or databases, as well as the specific implementation algorithms.

The depth sensitivity of ion beam analysis, i.e., the correspondence between detected particle energy and areal density, arises from the slowing of incident particles in the target material. Although physically associated with discrete events, the average behaviour is modelled as stopping cross sections. For simulations, the semi-empirical models developed 
by Ziegler, Biersack and co-workers in the 70's are most commonly used. These high-energy models, appropriate for most ion beam analysis conditions, use a Bethe-Bloch formulation approach with parameters derived from a large database of compiled experimental measurements. Any projectile ion, any elemental target and a wide energy window from keV to $\mathrm{GeV}$ energies can be treated. The models continue to be developed and updated within the framework of the SRIM (TRIM) ${ }^{110}$ package. Accuracy is thought to be of the order of $5 \%$ for $\mathrm{MeV}{ }^{1} \mathrm{H}$ and ${ }^{4} \mathrm{He}$ projectiles, but worse for heavier ions and lower energies. The older formulations may be less accurate than the newer ones. Recently the SRIM package has included a module that can be directly incorporated into the code. Other databases also exist, including PSTAR, ASTAR, and MSTAR ${ }^{111,112,113}$, for protons, alpha particles and heavier projectile ions, and an empirical formula for ions with energies of 0.1-1.0 MeV/amu in elemental targets ${ }^{114}$. The KKKNS compilation ${ }^{115}$ is useful for particular ion/target combinations, including the important case of $\mathrm{He}$ in $\mathrm{Si}$.

The stopping in compound samples and mixtures is usually treated in simulations by using the Bragg additivity rule. In addition, stopping cross sections are presumed to be independent of target density. The vast majority of simulation packages neglect known deviations from these rules, although some corrections and modifications are in use to improve accuracy.

Quantification of atomic concentrations is based on the scattering or reaction cross sections, which are assumed known in the data analysis. For elastic scattering in RBS and ERDA, the pure Coulomb scattering or Rutherford scattering cross sections can be incorporated analytically. The validity of the Rutherford model is, however, restricted to an energy window for a given projectile, target and scattering geometry. The low energy limit is set by electronic screening and is usually treated in simulations as a few percent correction ${ }_{116,117,118}$. Recently an algorithm for the efficient computation of screened Coulomb interatomic 
scattering has been presented ${ }^{119}$ The high-energy limit is set by the onset of interactions between the projectile and the atomic nucleus. Above this threshold, elastic scattering cannot in general be predicted by theoretical models, e.g., the optical model or the R-matrix theory, without experimental data to establish model parameters. Used with adequate experimental data, however, these models are very useful in extrapolating cross sections to angles and energies where data are not available $120,121,122,123,124,125$. There are a several computer databases of scattering cross sections available (NRABASE ${ }^{126}$, SIGMABASE ${ }^{127}$ ) containing data mostly for ${ }^{1} \mathrm{H}$ and ${ }^{4} \mathrm{He}$ ions backscattering from light elements for some fixed scattering angles relevant for ion beam analysis. There is a growing need for additional data, as well as for the critical evaluation of data and the development of additional theoretical model calculations. A code SIGMACALC for calculating the cross sections from tabulated theoretical model parameters is under development by A. Gurbich under the auspices of the IAEA. This action has also led to the integration of NRABASE and SIGMABASE into a single database called IBANDL ${ }^{128}$.

The internal representations of the models and/or databases, and the algorithms for implementation, differ from code to code. These differences are likely to produce additional deviations in simulation results beyond those attributable to the input data or models.

\section{Basic simulation status}

It is reasonable to compare ion beam analysis simulation codes since the fundamental physics of RBS, ERDA and NRA is well established and there is substantial similarity in the basic algorithms of must current packages. Almost all of the codes developed for general purpose analysis have adopted the indirect simulation method, using similar basic algorithms of energy loss calculations based on sub-division of a hypothetical layered target structure 
into thin slices. Calculation of stopping and scattering cross sections are also, in principle, similar. All ultimately achieve, as a result of data analysis, substantial agreement between the experimental and theoretically simulated spectra, yielding good absolute accuracy in spectrum analysis and sample characterization.

The codes, however, differ widely in the details of how they handle the fundamental physics and the basic simulation procedures. Whether this leads to differences in the calculated spectra remains untested. We now cover several aspects where multiple approaches can be implemented.

The sub-division of target layers into slices is handled in many ways. The simplest algorithms adopt a fixed pre-determined maximum slice thickness. This can lead to poor accuracy in some cases, especially when the angle of incidence and detection differ widely. Alternatively, a different fixed sub-division can be adopted for incoming ions and for the outgoing detected ions. The energy loss through any given slice, dependent on the local stopping power, is usually kept small to retain accuracy in the simulations and hence sets a maximum slice thickness for a given ion and target. Some codes take a mixed analytical/numerical approach by using expansions of the stopping power and cross sections to handle much thicker slices with comparable accuracy. Equally, since slices that are substantially thinner than the energy resolution (spread) at a given depth are computationally inefficient, efficiency can be improved by dynamically adjusting the slice thicknesses taking the stopping power and the energy resolution at the current depth into account.

The most widely used method is to follow the beam on its way from the surface into the sample where it is scattered at a given depth, and then follow each of the scattered particles on the way out to the surface. This leads to a table of energies of the detected beam that must then be interpolated to the energies of the MCA bins actually measured. In the retrograde method the beam is followed in time-reversed mode, starting with the energy 
actually detected. This can lead to a more efficient calculation since fewer interpolations are required.

While Rutherford scattering cross sections are handled analytically with corrections, non-Rutherford cross sections are almost invariably implemented as look-up tables. Simple interpolations for the required energy can be made, but this will lead to inaccuracies for very sharp resonances. Various solutions to this problem have been adopted, such as using the cross section in integrated form (thus using the correct total cross section for a given slice), or by forcing the slices to be sufficiently thin to cover all the points in the known cross section table, which is slower but may be more accurate ${ }^{129}$. Tabulated values may also be fit to continuous differentiable functions (such as a spline) and handled analytically, or implemented as specific nuclear model calculations.

Stopping power cross sections can also be stored as look-up tables and interpolated during calculations. This approach is fast but may ignore variation of the stopping power inside a slice. If a differentiable continuous function is used to represent the stopping curve, this variation can be taken into account analytically, leading to improved precision at some computational cost.

The discrete nature of ion stopping events leads to energy loss straggling and a spread in energy as the incident beam penetrates a target. Implementations of straggling vary widely, ranging from being completely ignored to detailed algorithms, which address asymmetric distributions near the surface. The physics included in some of the more advanced energy loss straggling algorithms will be covered in the next section. Most of the basic simulations use a Gaussian-shaped resolution function with varying width through the sample. This straggling spread is convoluted with a detector resolution function, also normally Gaussian, to yield the final spectrum. 
Finally, some codes have restrictions on the number of elements and layers allowed in the sample description. When restrictions on the number of slices exist, problems can arise when a very thin slice description is required (for instance, in high-resolution experiments using a magnetic spectrometer, or if the cross section has very many sharp resonances).

In the following sections, finer details and capabilities of the simulation codes are reviewed. This review does not purport to discuss the physical origin of all of these phenomena, but rather only their implementation in data analysis codes.

\section{Further simulation physics}

While all simulation codes treat basic ion stopping and scattering phenomena, many of the subtle features in spectra arise from more complex interactions. Some of these effects include energy loss straggling, multiple and plural scattering. Energy loss straggling, as mentioned above, is a consequence of the statistical nature of the energy loss and results in a degradation of the spectrum with depth. The term plural scattering describes trajectories where the ion suffers several large angle scattering events before being detected. A particular case is double scattering, corresponding to two large angle events. Multiple scattering refers to the succession of many small angle scattering events, leading to an angular broadening in the beam path. This separation between plural and multiple scattering is, to some extent, arbitrary as it depends on the definitions for "large" and "small" angles. However, the effects on the experimental spectra are quite distinct, and the theoretical treatment of plural and multiple scattering is usually treated separately.

Some codes do not model energy loss straggling. Those that do implement the Bohr model ${ }^{130}$, with or without the Chu correction ${ }^{131,132}$. Another issue, that pertains not only to energy loss straggling but to all energy resolution effects, is the slope of the stopping power 
with energy which can broaden or narrow the distribution, an effect first treated by Tschalär $133,134,135$

The energy straggling distribution function is not strictly Gaussian, an effect which can be taken into account either by using a measured resolution function, or by some convenient analytic form. The former has not, as far as is known, been implemented in any codes while the latter is incorporated in some. (Although non-Gaussian distributions have not been used in direct simulations, such a resolution function has been used to deconvolute the effect of the system resolution from data ${ }^{136}$ ), A particular case is the asymmetric energy loss straggling near the surface of the sample, which no code for RBS, ERDA, or non-resonant NRA currently implements. This effect is likely to be observable only with high-resolution systems.

To faithfully reproduce spectral features, especially from sharp resonance scattering, the energy dispersion from straggling must also be incorporated into the scattering calculations of each layer. For any layer, straggling of the incident beam energy creates a distribution of incident energies, which scatter with varying cross sections to yield a modified distribution of scattered energies. This new energy distribution then propagates with further straggling on the outward path. This is the most accurate method, and possibly the only one able to reproduce the signal of sharp resonances occurring deep in the sample. However it is difficult to implement and increases calculation times by several orders of magnitude. Codes implementing such algorithms include the BS1 code, dedicated to the RBS analysis, and SPACES, a code for resonant NRA .

Multiple scattering models are based on the Sigmund theory ${ }^{137}$, extended by Amsel et al. ${ }^{138}$ and implemented by Szilágyi et al. . Multiple scattering manifests itself mostly as an additional contribution to the energy spread and as small low energy tails on signal edges arising from non-Gaussian wings in the energy distribution. Most analytic codes do not 
directly calculate multiple scattering. However, the energy resolution loss effects can be incorporated, including or not non-Gaussian resolution function shapes. The theory assumes symmetrical scattering, which is not true in grazing angle experiments, leading to increasing inaccuracies with depth. The small tails have not, so far, been modelled analytically. The most realistic calculations, including all the effects, can currently only be treated properly with Monte Carlo methods ${ }^{98-107}$. In this case, multiple scattering cannot be distinguished from plural scattering, which is thus also included.

Plural scattering leads to an increase of the yield at low energies, and to a low energy background ${ }^{139}$. Most analytic codes do not fully model it, but double scattering has been successfully modelled for RBS ${ }^{12,13,14,103}$, with current approximations for ERDA being still unsatisfactory ${ }^{140}$. All models imply the calculation of many trajectories, requiring several orders of magnitude more time than single scattering and leading to fairly long calculations. Most implementations impose a strict minimum scattering angle in the calculations (to avoid the singularity in the Rutherford cross section at $0^{\circ}$ ), leading to difficulties in modelling grazing angle experiments. Refinements taking into account the actual path of each trajectory, in comparison with the primary scattering event, can be made ${ }^{141}$. Some analytic models have been proposed, but are of limited applicability ${ }^{142,143}$.

\section{Measurement system effects}

Experimental spectra are also influenced by physical realities and limitations of the accelerators, detection systems, and methods of data acquisition. Several of these effects, and the methods for handling them in simulation packages, are considered next. There are large variations in this regard in the codes. This section will emphasis effects associated with solid- 
state detectors, since most codes model only such detectors. A few packages are able to handle more sophisticated detection systems, such as time-of-flight, and are briefly discussed.

Geometric straggling for solid-state energy dispersive particle detectors (the most commonly used detectors in ion beam analysis) arise from the finite size of the incident beam, finite spread in angle of incidence, detector solid angle, and geometric path length distribution. Both kinematic and stopping power effects arise, with the two effects fully correlated ${ }^{144,94}$. This leads to an extra apparent degradation of energy resolution (including at the surface), and may lead to minor changes in yield if the scattering cross section varies strongly with scattering angle. While many codes ignore this effect, some implement model for circular or rectangular detector shapes, as far as it affects the energy resolution (but not the yield). A summation of partial spectra over a distribution of exit angles can also be easily executed, but this approach is both slower and less accurate.

Geometric straggling for other detection systems requires a detailed understanding of the overall system, such as timing error in TOF systems, and is not yet supported in any analytic code. Only Monte Carlo codes currently simulate this effect properly.

Beam energy spread in the incident beam is an additional energy broadening that appears before any straggle broadening. It is normally approximated as a Gaussian distribution and handled as part of the system resolution.

The detection system contributes significantly to the energy spread, depending on both the ion and the energy. For surface barrier detectors, this broadening is fairly constant with energy for $\mathrm{H}$ and $\mathrm{He}$ in the energy range normally used in ion beam analysis. However, for heavy ions, the dependence is substantial and must be considered. Separate energy-dependent system resolution calculations for each ion can be realised.

Absorber foils in ERDA can be handled either as part of the sample or as part of the detection system. When considered as part of the sample, energy loss, straggling, foil 
inhomogeneity, and all other effects normally considered are included in a natural way. Other approaches include: measuring and calibrating the foil as part of systems characteristics; precalculating effects of the foil on beam energy and straggling as a function of incident ion and energy; or propagating the energy distribution through the foil. Monte Carlo calculations describe foils in a natural way.

Pulse pileup occurs when two ions reach a detector within a time response window, leading to a single erroneous event being recorded ${ }^{145,146,147}$. Two low energy events are lost, replaced by one event at an energy that depends on the time lag between the two ions and the electronic pulse shape; the observed energy lying between that of the first event and the summed energy of both ions ${ }^{148,149}$. This effect is proportional to the count rate, and hence important for high current or high $\mathrm{Z}$ measurements. Pulse pileup manifests itself as a high energy tail on peaks, and as changes in the exact shape of a plateau. Thus simple extrapolations of the signal observed at high energies are inadequate. Some codes simulate pileup as the auto-convolution of the raw data ${ }^{150}$, or more precisely as a convolution of the data with the electronic pulse shape (dependent on the shaping time constant). The autoconvolution approach is fast, but only accurate if a pile-up rejector is used during the measurement. Other codes adopt more sophisticated approaches . However, unstable beam fluence (and thus count rate) during the experiment, as well as the low level MCA discrimination point prevent knowing the true yield to low energies and limit accuracy.

The pulse height defect for solid-state energy dispersive particle detectors is the difference between the actual energy of the ion incident on the detector and the energy reported ${ }^{151}$. This defect arises from several different phenomena. First, ions lose energy traversing the dead layer of the detector. Second, some of the energy lost in the active layer does not lead to the creation of electron-hole pairs, but non-ionising processes such as phonon or lattice vacancy creation, related to the nuclear stopping. A third contribution arises from 
the formation of a dense cloud of electron-hole pairs along the ion trajectory, with a higher rate of recombination, and an additional screening of the electric field increasing the collection time and recombination probability ${ }^{152}$. A severe case may occur in NRA, when the energy of the reaction product is so high that ions are not stopped within the sensitive zone of the detector. In such cases, the normally Gaussian shaped amplitude response quickly widens and becomes asymmetric due to energy straggling in the depletion layer and other statistical effects ${ }^{153}$. Finally, it has been proposed that the energy required to create electron-hole pairs may depend on the atomic number of the ion ${ }^{154}$.

These effects lead to an apparent non-linear and ion-dependent energy calibration. In $\mathrm{H}$ and He scattering, it may represent a $1 \%$ difference in calculated yield ${ }^{155}$. For heavy ion scattering, these effects can be major. Few codes directly model this effect. Some implement a polynomial energy calibration, which, if accurate, mask the effects. A full analytic calculation of the dead layer and of the nuclear stopping effects (which account for most of the pulse height defect) can be made, with the remaining effects being treated as a non-linear energy calibration $^{155,156}$.

Slit scattering leads to the production of the low energy incident ions with a broad angular dispersion. It depends critically on the experimental configuration, and leads mostly to a low energy background, fairly similar to that arising from plural scattering ${ }^{157,158,159}$. Only Monte Carlo codes currently account for this effect.

Sample charging, which creates an electric field at the surface of the sample, effectively changes the energy of the incident beam. In general, it is not modelled in most data analysis codes though the BAS code has been developed for this special case.

\section{Sample effects}


The sample effects discussed below include roughness, lateral inhomogeneity, porosity and crystalline structures. These effects are handled minimally in only a few of the existing data analysis codes. They can be treated in great detail in a Monte Carlo simulation 98-107. The results of such simulations can then be parameterised and fed into analytical models to be incorporated in continuum data analysis codes.

Roughness is a very poorly defined concept, with a multitude of types and length scales, requiring potentially different approaches in simulation. A minimum classification should include, at the very least, substrate roughness, layer roughness, and surface roughness, noting that these concepts are, in most cases, correlated. For instance, a given substrate roughness may be propagated through all layers up to the surface, or a surface pit may extend down through several layers.

An additional difficulty is that ion beam analysis data are seldom adequate to characterise the roughness. For instance, the effects of interdiffusion and of layer roughness (with equivalent average depth) in a given interface are undistinguishable by RBS. Also, inhomogeneous layer thickness may be analysed as sample corrugation (although in some cases collecting spectra at different angles may help to distinguish between the cases ${ }^{160}$ ). With few exceptions, a-priori knowledge of the roughness characteristics are required for correct analysis of the ion beam analysis data. This knowledge never really exists, as various microscopies probe very different spatial scales. None of the standard microscopy methods, i.e.,transmission electron microscopy, scanning electron microscopy (SEM), or atomic force microscopy can probe areas comparable to those averaged with the ion beam. Larger areas can be analysed with SEM, but only the surface is accessible and propagation of this roughness into deeper layers must be assumed. In this respect, ion beam analysis of roughness requires extra knowledge, complemented by further assumptions, and is thus approximate. 
Different methodologies for treating roughness effects have been developed 15,49,73,91,92,98,161- $\quad 175$. The most accurate line of study is Monte Carlo simulation of known surface and interface features, but this also requires the most prior knowledge (or prior assumptions). In analytic codes, one approach is the summation of partial spectra over a distribution function of some sample characteristics, such as surface height distribution, film thickness distribution, step height distribution, or other. Correlation effects (such as incidence through a hill and exit through a valley and the like) are usually neglected. Addressing such effects requires detailed knowledge of the roughness distribution. By using Bayesian inference, it can be also used to derive roughness distributions from measured RBS spectra ${ }^{176}$ Another analytic approach, used for small levels of roughness, is to approximate its effect as an equivalent energy broadening in spectral features for given model types of roughness. This method is fast but has the most stringent limits of applicability.

Lateral inhomogeneities also exist over multiple length scales, leading to varying effects and different simulation approaches. If the length scale is large compared to the ion entrance and exit points, a single structure is probed by each given ion. In this case, partial spectra summation over distribution of sample structures is reasonable. However, if each ion crosses multiple structures along its path, only Monte Carlo simulations of known structures are likely to be accurate. In general, lateral inhomogeneity is more effectively studied using microbeam techniques.

Porosity can also have different scales. In nano-porosity, pore-induced stopping power changes must be considered. Analytic methods for the statistical averaging of the effect of pores (or inclusions, of which nano-pores are one particular case) have been developed for specific pore configurations. On the other hand, microporosity can be similar to the lateral inhomogeneity and/or roughness conditions, depending on the exact structure considered. 
All the above mentioned sample effects, i.e., rough surface, lateral inhomogeneity, inhomogeneity in the thickness, voids, etc., increase the energy spread and lead to a corresponding decrease in the depth resolution. In this case a new energy spread contribution can be introduced which is connected to the structure of the sample, the so called "structureinduced energy spread”. Investigating its dependence on the experimental parameters, more often on the tilt angle, allows one to obtain information on the sample structure, e.g., surface roughness of the substrate, inhomogeneity of the layers in multilayer systems ${ }^{177}$ and pore structure in porous silicon $178,179,180,181$. To interpret the measurements on porous structures, Monte Carlo simulations were performed by the RBS-MAST code taking a 3D sample structure into account.

The simulation of crystalline structures, including channelling and the effect of extended and point defects, is not normally handled in analytic codes. Some codes include limited models for given structures and types of defects that can be used for data analysis ${ }^{71}$. To determine the depth profile of the defect distribution the knowledge of stopping powers of charged particles in the channelling direction of single crystals is very important ${ }^{182},{ }^{183}$. In the general case, Monte Carlo programs are used for simulating channelling and defects ${ }^{184,185}$.

\section{Profile extraction}

In realistic samples, the distribution of elements usually varies continuously with depth. The simple reduction of this distribution to layers of constant composition in simulation codes is thus often inadequate. There are a great variety of methods to handle the description of depth profiles and their extraction from the data.

The direct method described in the section II above converts each yield in a given channel into a concentration value. This relies either on an iterative calculation of stopping 
powers from the data, or from stopping powers calculated for a user-input structure. Either way, it is necessary to separate the signals coming from different elements from each other, or at least that any signal superposition can be unambiguously solved. This is possible in many cases, particularly in heavy ion ERDA with mass or Z sensitive detectors, where the signal of each element is separated. The biggest inconvenience of this method, however, is that the profiles derived are not real concentration depth profiles since they still have the energy resolution convoluted. Other effects such as multiple scattering induced spread or geometrical straggling will also distort the profile obtained. Sample effects such as roughness will also result in an apparent concentration gradient, which is not real. One method of taking this into account is to use the apparent depth profiles generated with the direct method as raw data for a Bayesian inference analysis, based on a Monte Carlo calculations that considers all other effects, in order to derive the final depth profile ${ }^{186}$.

The common goal of ion beam data analysis software that employs the indirect method is the extraction of concentration and thickness of samples, or more generally, of depth profiles. The first question is how the code can describe the sample. Practically all codes implement a layer description of the sample, where each layer is considered to have a constant composition. In this case, a slowly changing concentration must be described by many small layers with slightly different concentrations, in a way that, considering the depth resolution, the calculated spectrum is similar to the measured one. Some codes implement functional dependence of elemental concentrations. These are normally then transformed during the calculations into thin slices of constant composition. The difference to a layer specification is then mostly only in the degree of user control of the code, and of convenience in the specification of given profiles.

The sample features considered in the previous section also belong to the sample specification (to be extracted from the data) and are included in some codes. 
Given a well-defined sample structure, a well-defined definition of the physics included in a code, and a well-defined computer simulation of that physics, the corresponding spectrum can be calculated. The inverse problem, of having a spectrum, the physics and its application in the code, to calculate the corresponding sample structure, is an ill-posed problem in the general case $17,18,19,187,188,189,190$. This means that there may be more than one solution consistent with the spectrum. Furthermore, if the spectrum is an experimental one with errors associated, in general there is no solution that exactly satisfies the conditions of the problem. Instead, there will be many solutions consistent with the data within the errors.

Also, multiple spectra are often collected from the same sample, using different experimental configurations that may include different geometrical arrangements, beam ion and energy, or detection system. Each spectrum normally accesses different information and has different statistics. For instance, an ERDA spectrum may have very poor statistics, but it can be the only information available about the $\mathrm{H}$ content of a sample. The final depth profile obtained should describe well all the data collected.

Moreover, the data analyst normally has prior information over the sample at their disposal. This can be other experiments already done, information about the origin and nominal composition of the sample (that may or may not correspond to the real one), chemical information about the proportions in which given elements form bonds, or any other prior beliefs about the sample. It is normally useful to incorporate this information in the data analysis, and often it is essential to do so in order to remove ambiguities in the final solution. However, the beliefs may or may not be true, so the question of how much should they constrain the final solution is also important.

Many different approaches are used to tackle these issues. All codes can generate a calculated spectrum for a given sample structure and compare it to experimental data, leading to interactive analysis in which the user tries to guess which depth profile best simulates the 
data, given any prior constraints (that the user may decide to relax during the analysis). If multiple spectra were collected, the user normally first simulates one, proceeds to the next, corrects the depth profile already obtained, and so on. The analysis is done until the user decides the simulation is good enough or runs out of patience. These are subjective criteria, but possibly still the most widely used in ion beam data analysis.

In semi-automated procedures, the user inputs an initial guess, which is then refined automatically by the computer using some criterion such as the $\chi^{2}$ test . Normally, the initial guess must include the number of layers, and a good initial guess is essential to reach a good final solution.

Different algorithms to obtain depth profiles in a fully automated procedure have been developed. Such a procedure includes a direct analytic inversion of the data into a composition profile, provided that regularizing conditions are imposed . These can be a priori information or simply the rejection of any structure thinner than the depth resolution. The disadvantage of this method is that it is mathematically rather complex.

A fairly new class of algorithms can also be employed, such as artificial neural networks or genetic algorithms. Artificial neural networks have the disadvantage of being developed for specific systems, thus not being suited for a general data analysis package. The genetic algorithm does not guarantee to find the general minimum of the target function (e.g. $\chi^{2}$ ). In both cases, prior information is difficult to introduce.

The simulated annealing algorithm has been used to solve the inverse problem, at least in the sense that it can obtain the minimum $\chi^{2}$ value, taking into account all the spectra and all the prior information available ${ }^{74,75,191,192}$. It has the further advantage of not requiring an initial guess. It does require, in order to provide meaningful solutions, some regularization method, which can be simply that the final solution obtained should have the minimum 
number of layers that leads to a good fit, by penalising in the $\chi^{2}$ function the introduction of the extra layers. This is not a systematic approach, but in practice works well.

The biggest disadvantage of the methods already described is that they do not provide the analyst with errors on the final results, that is, on the depth profile obtained. Bayesian inference is a systematic method to do this. All the information present in the data can be extracted, and additional prior information can be taken into account. This allows, for instance, to obtain confidence limits for the depth profile. All implementations for ion beam analysis ${ }^{186,187,193,194}$ use the Markov chain Monte Carlo integration method, which leads to calculation times several orders of magnitude larger than other analysis methods. Some implementations also use the maximum entropy prior, which ensures, in a systematic way, that the final solution is the simplest consistent with the data. However, current implementations are still fairly complicated, and in practice are used almost exclusively by the code authors. The long calculation times also mean they are not yet suited for routine data analysis, but progress is being made.

\section{Other experimental conditions}

In addition to ion beam analysis techniques based on the elastic collision of atomic particles, a number of other techniques exist. Various experimental techniques can be coupled together to give a more comprehensive view of the sample under study.

In resonant NRA one measures the charged particle yield in a given energy window versus the incident beam energy. This is the reason to exclude this technique here, since with RBS, ERDA and non-resonant NRA, the beam energy is fixed, leading to similar calculations. Nevertheless, it is feasible to integrate resonant NRA in a code for RBS, ERDA, and nonresonant NRA. 
PIXE and PIGE detect $\mathrm{x}$-rays and $\gamma$-rays, both leading to different analysis methods. Nevertheless, these techniques are complementary to RBS and ERDA, and it would be useful to have all these techniques integrated in one single analysis package.

The treatment of more elaborate detection techniques could also be incorporated in data analysis codes. Detection systems such as magnetic analysers, other position sensitive detectors or TOF, are increasingly used, and efforts towards implementing their specific features (including direct analysis of time spectra) are desirable.

Microbeam tomography, normally coupled to other techniques such as PIXE, has been excluded here since it has specific analysis methods based on image analysis (often coupled to quantitative analysis of overall concentrations, or even analysis of 3D structures). Analysis of microbeam and macro beam data will very likely continue to be made by separate communities using different software packages.

\section{Conclusion}

We have reviewed the major issues concerning modern data analysis of RBS, ERDA, and non-resonant NRA data. In Tables 1 through 8 we present some characteristics of 12 ion beam data analysis software packages that employ the indirect method based on analytic simulations (note however that many of the codes also perform direct method calculations). This listing is not exhaustive, since more codes exist which are not mentioned here. In some cases the authors did not wish their code to be included, in other cases the authors could not be contacted. Codes dedicated to very specific problems, or codes that use only the direct method, were not included. Finally, some codes may have been disregarded due to our own ignorance of their existence. Note also that Monte Carlo codes were excluded from the comparison because they are essentially different from analytic codes. 
We stress that inclusion or exclusion of a code in these tables bears no meaning on its correctness and accuracy. The International Atomic Energy Agency is currently organising an intercomparison exercise of ion beam data analysis software dedicated to programs using the indirect method to simulate theoretical spectra and analyse experimental data of RBS, ERDA, and non resonant NRA ${ }^{195}$. The desired primary outputs are: to validate existing and newly developed methods; to determine the absolute accuracy achievable from well defined measurements of well defined samples; to estimate the errors in the information extracted by the different programs; to quantify differences produced by different physics, algorithms, and implementations used. These outputs will be used to: drive developments in new physics and improved algorithms; facilitate user training in learning to extract correct information; assist regression testing of modifications in existing codes and models; drive improvements in software documentation and usability; evaluate and validate existing and new databases.

The most important methods and approaches employed in the different codes were discussed. The stopping power and scattering cross section data bases employed, the iontarget interaction physics, the experimental and detection system, and structural characteristics of the samples all have a strong impact on the data, and the way they are modelled in different codes and algorithms were discussed in detail. Limitations in the existing codes and perspectives for further developments are given. The importance of ascertaining the correctness and accuracy of different methods and codes used in ion beam data analysis is stressed.

Finally, traditionally each code has been developed independently from other codes, leading to multiplication of efforts. Also, each code has developed its own input and output data formats, different definitions and conventions of quantities and units, making interchange of information difficult. Some degree of standardisation, and in particular the development of a universal data interchange format, would be extremely desirable. Increased cooperation, and 
ideally sharing of algorithms and source code between authors, would lead to faster developments and ultimately better codes.

\section{Acknowledgements}

We would like to thank the International Atomic Energy Agency for support, and also the code authors that provided information about their codes: Leonid Kuzmin (BEAM EXPERT),

Mitsuo Tosaki (BS1), Vlastimil Bohac (DVBS), James Ziegler (IBA), Robert A. Weller (Particle Solid Tools), Yves Serruys (PERM), Endre Kótai (RBS). Partial support of the Hungarian OTKA grant No.: T 046238 is acknowledged. 


\section{Appendix: Status of 12 ion beam analysis software packages}

TABLE 1. General information about analysis programs.

\begin{tabular}{|c|c|c|c|}
\hline $\begin{array}{l}\text { Analysis } \\
\text { Program }\end{array}$ & Technical Contact & $\begin{array}{c}\text { Initial code } \\
\text { date }\end{array}$ & Operating Systems \\
\hline BEAM & Leonid Kuzmin & 1986 & DOS (or \\
\hline EXPERT & $\begin{array}{l}\text { Institute for Nuclear Research, Russian Academy of Sciences, Russia. } \\
\text { Present contacts: Dimitry Kogan, DmitryKogan@rambler.ru and } \\
\text { Alexander Kazantsev, kazants@mail.ru }\end{array}$ & & emulators) \\
\hline BS1 & $\begin{array}{l}\text { Mitsuo Tosaki } \\
\text { Radioisotope Research Center, Kyoto University } \\
\text { Kyoto 606-8502, Japan } \\
\text { tosaki@barium.rirc.kyoto-u.ac.jp }\end{array}$ & 1999 & UNIX (Windows) \\
\hline DEPTH & $\begin{array}{l}\text { Edit Szilágyi } \\
\text { KFKI Research Institute for Particle and Nuclear Physics } \\
\text { Budapest, Hungary } \\
\text { szilagyi@,rmki.kfki.hu; www.kfki.hu/ ionhp/ }\end{array}$ & 1994 & $\begin{array}{l}\text { DOS (or } \\
\text { emulators) } \\
\text { (New version will } \\
\text { be Windows) }\end{array}$ \\
\hline DVBS & $\begin{array}{l}\text { Vlastimil Bohac } \\
\text { Institute of Physics, Slovak Academy of Sciences, Bratislava, Slovak } \\
\text { Republic } \\
\text { and Dmitryi Shirokov } \\
\text { (JINR, Dubna, Russia at the time of creating program) nowadays - } \\
\text { Phase Forward Incorporated, Waltham, MA, USA } \\
\text { bohac@savba.sk; dshirokov@phaseforward.com; www.fu.sav.sk }\end{array}$ & $\begin{array}{l}1990 \\
\text { (published in } \\
\text { 1994) }\end{array}$ & $\begin{array}{l}\text { DOS (or } \\
\text { emulators) }\end{array}$ \\
\hline GISA & $\begin{array}{l}\text { Eero Rauhala } \\
\text { University of Helsinki, Helsinki, Finland } \\
\text { and Jaakko Saarilahti, Technical Research Center of Finland } \\
\text { Eero.rauhala@,helsinki.fi; Jaakko.Saarilahti@vtt.fi }\end{array}$ & 1983 & $\begin{array}{l}\text { DOS (or } \\
\text { emulators) }\end{array}$ \\
\hline IBA & $\begin{array}{l}\text { James Ziegler } \\
\text { United States Naval Academy } \\
\text { Annapolis, MD, USA } \\
\text { Ziegler@SRIM.org; www.SRIM.org }\end{array}$ & 1968 & $\begin{array}{l}\text { Windows, UNIX, } \\
\text { OS2 }\end{array}$ \\
\hline Particle & Robert A. Weller & 1992 & All systems with \\
\hline Solid Tools & $\begin{array}{l}\text { Vanderbilt University } \\
\text { Nashville, TN, USA } \\
\text { robert.a.weller@,vanderbilt.edu }\end{array}$ & & $\begin{array}{l}\text { Mathematica } 4.1 \\
\text { and higher. }\end{array}$ \\
\hline PERM & $\begin{array}{l}\text { Yves Serruys } \\
\text { CEA-Saclay, France } \\
\text { Yves.Serruys@,cea.fr }\end{array}$ & 1990 & Windows \\
\hline RBX & $\begin{array}{l}\text { Endre Kótai } \\
\text { KFKI Research Institute for Particle and Nuclear Physics } \\
\text { Budapest, Hungary } \\
\text { kotai@,rmki.kfki.hu }\end{array}$ & 1985 & Windows \\
\hline RUMP & $\begin{array}{l}\text { Mike Thompson } \\
\text { Dept. of Materials Science, Cornell University } \\
\text { Ithaca, NY USA }\end{array}$ & 1983 & $\begin{array}{l}\text { Windows, Linux, } \\
\text { UNIX, OS2 }\end{array}$ \\
\hline & mot1@,cornell.edu; www.genplot.com & & \\
\hline SIMNRA & $\begin{array}{l}\text { Matej Mayer } \\
\text { MPI for Plasma Physics } \\
\text { Garching, Germany } \\
\text { Matej.Mayer@ipp.mpg.de; www.rzg.mpg.de/ mam/ }\end{array}$ & 1996 & Windows \\
\hline WiNDF & $\begin{array}{l}\text { Nuno Barradas } \\
\text { Technological and Nuclear Institute } \\
\text { Sacavem, Portugal } \\
\text { nunoni@itn.pt; www.ee.surrey.ac.uk/Research/SCRIBA/ndf/ }\end{array}$ & 1997 & Windows, UNIX \\
\hline
\end{tabular}


TABLE 2. Current status of analysis programs.

\begin{tabular}{|c|c|c|c|c|c|c|}
\hline $\begin{array}{l}\text { Analysis } \\
\text { Program }\end{array}$ & Current Status & $\begin{array}{l}\text { Current } \\
\text { Version }\end{array}$ & $\begin{array}{c}\text { Current } \\
\text { Programming } \\
\text { Language } \\
\end{array}$ & $\begin{array}{c}\text { Date of last } \\
\text { distributed } \\
\text { documentation } \\
\end{array}$ & Distribution Mode & $\begin{array}{c}\text { Status of } \\
\text { source code }\end{array}$ \\
\hline $\begin{array}{l}\text { BEAM } \\
\text { EXPERT }\end{array}$ & In use. & 1.5.1 (1997) & $\begin{array}{l}\text { Borland } \\
\mathrm{C} / \mathrm{C}++\end{array}$ & 1994 & None. & $\begin{array}{l}\text { Restricted to } \\
\text { author -not } \\
\text { available. }\end{array}$ \\
\hline BS1 & $\begin{array}{l}\text { Active } \\
\text { Development }\end{array}$ & $2.0(2002)$ & Fortran $90(77)$ & none & none & $\begin{array}{l}\text { Restricted to } \\
\text { author -not } \\
\text { available. }\end{array}$ \\
\hline DEPTH & $\begin{array}{l}\text { Active } \\
\text { Development }\end{array}$ & $2.0(1998)$ & $\begin{array}{l}\text { Turbo Pascal } \\
\text { (Delphi Pascal } \\
\text { for Windows) }\end{array}$ & 1995 & $\begin{array}{l}\text { No charge. } \\
\text { Downloadable from } \\
\text { the WEB. }\end{array}$ & $\begin{array}{l}\text { Restricted to } \\
\text { author -not } \\
\text { available. }\end{array}$ \\
\hline DVBS & In Use & 1995 & $\begin{array}{l}\text { Microsoft } \\
\text { Fortran } 77\end{array}$ & 1995 & $\begin{array}{l}\text { No charge. } \\
\text { Downloadable from } \\
\text { WEB upon request }\end{array}$ & $\begin{array}{l}\text { Restricted to } \\
\text { author -not } \\
\text { available. }\end{array}$ \\
\hline GISA & In Use & 3.991 (1993) & $\begin{array}{l}\text { Quick Basic } \\
4.5\end{array}$ & $\begin{array}{l}1992 \\
\text { published, } \\
1995 \text { last } \\
\text { manual }\end{array}$ & $\begin{array}{l}\text { No charge. Write to } \\
\text { author for copy. }\end{array}$ & $\begin{array}{l}\text { Restricted to } \\
\text { author -not } \\
\text { available. }\end{array}$ \\
\hline IBA & In use. & - & APL & 2000 & $\begin{array}{l}\text { No charge. } \\
\text { Downloadable from } \\
\text { www.SRIM.org. } \\
\text { Must get compiler } \\
\text { from IBM (free). }\end{array}$ & $\begin{array}{l}\text { Source code } \\
\text { available. }\end{array}$ \\
\hline $\begin{array}{l}\text { Particle } \\
\text { Solid Tools }\end{array}$ & $\begin{array}{l}\text { Active } \\
\text { Development }\end{array}$ & 1) & Mathematica & Not known. & $\begin{array}{l}\text { Available from the } \\
\text { author. }\end{array}$ & $\begin{array}{l}\text { Source code } \\
\text { available. }\end{array}$ \\
\hline PERM & $\begin{array}{l}\text { Active } \\
\text { Development }\end{array}$ & 2003.02 & $\begin{array}{l}\text { Digital Visual } \\
\text { Fortran }\end{array}$ & 2002 & No charge. & $\begin{array}{l}\text { Restricted to } \\
\text { author -not } \\
\text { available. }\end{array}$ \\
\hline RBX & $\begin{array}{l}\text { Active } \\
\text { Development }\end{array}$ & $5.1(2002)$ & Delphi Pascal & 1992 & $\begin{array}{l}\text { No charge. Write to } \\
\text { author for copy. }\end{array}$ & $\begin{array}{l}\text { Restricted to } \\
\text { author -not } \\
\text { available. }\end{array}$ \\
\hline RUMP & $\begin{array}{l}\text { Active } \\
\text { Development }\end{array}$ & $4.00(2004)$ & $\begin{array}{l}\text { Microsoft C6.0 } \\
\text { Most Unix C }\end{array}$ & $\begin{array}{l}1992 \text { with } \\
\text { enhancement } \\
\log \end{array}$ & $\begin{array}{l}\text { Commercial through } \\
\text { Computer Graphics } \\
\text { Service - } \$ 250 \text {. } \\
\text { Evaluation copies } \\
\text { available on WEB. }\end{array}$ & $\begin{array}{l}\text { Source code } \\
\text { available. }\end{array}$ \\
\hline SIMNRA & $\begin{array}{l}\text { Active } \\
\text { Development }\end{array}$ & $5.70(2005)$ & $\begin{array}{l}\text { Delphi Pascal } \\
6.0\end{array}$ & 2005 & $\begin{array}{l}\text { Commercial through } \\
\text { MPI for Plasma } \\
\text { Physics - } \$ 250 \text {. } \\
\text { Evaluation copies } \\
\text { available on WEB. }\end{array}$ & $\begin{array}{l}\text { Restricted to } \\
\text { author -not } \\
\text { available. }\end{array}$ \\
\hline WiNDF & $\begin{array}{l}\text { Active } \\
\text { Development }\end{array}$ & $8.0(2005)$ & $\begin{array}{l}\text { Digital Fortran } \\
90 \text { for } \\
\text { Windows } \\
\text { version }\end{array}$ & 2004 & $\begin{array}{l}\text { Commercial through } \\
\text { Univ. of Surrey } \\
£ 2000 \text {. } \\
\text { Evaluation copies } \\
\text { available by request. }\end{array}$ & $\begin{array}{l}\text { Restricted to } \\
\text { author -not } \\
\text { available. }\end{array}$ \\
\hline
\end{tabular}

1) Various components of the system have differing individual version numbers. 
TABLE 3. User interface properties of the analysis programs.

\begin{tabular}{|c|c|c|c|c|c|c|}
\hline $\begin{array}{l}\text { Analysis } \\
\text { Program }\end{array}$ & $\begin{array}{c}\text { Primary } \\
\text { Interface } \\
\text { "nature" } \\
\end{array}$ & Primary simulation modes & $\begin{array}{c}\text { Maximum } \\
\text { spectrum size }\end{array}$ & $\begin{array}{l}\text { Spectrum } \\
\text { input } \\
\text { formats }\end{array}$ & $\begin{array}{l}\text { Scattering } \\
\text { information }\end{array}$ & $\begin{array}{l}\text { Graphic } \\
\text { Output }\end{array}$ \\
\hline $\begin{array}{l}\text { BEAM } \\
\text { EXPERT }\end{array}$ & Interactive & $\begin{array}{l}\text { Fully automated search; } \\
\text { manual iteration. }\end{array}$ & 512 & $\begin{array}{l}\text { MCA, } \\
\text { ASCII also } \\
\text { possible. }\end{array}$ & $\begin{array}{l}\text { Independent } \\
\text { files }\end{array}$ & Screen only \\
\hline BS1 & $\begin{array}{l}\text { Interactive } \\
\text { or batch }\end{array}$ & Manual iteration & - & & ASCII & Draft quality \\
\hline DEPTH & $\begin{array}{l}\text { Interactive } \\
\text { or batch }\end{array}$ & N/A & N/A & N/A & ASCII & N/A \\
\hline DVBS & Interactive & $\begin{array}{l}\text { Automated iteration. } \\
\text { Manual iteration is } \\
\text { supported by graphical } \\
\text { editor for concentration } \\
\text { profile. }\end{array}$ & 1024 & $\begin{array}{l}\text { Formatted } \\
\text { ASCII, } \\
\text { RUMP, } \\
\text { special } \\
\text { binary } \\
\text { format }\end{array}$ & $\begin{array}{l}\text { Independent } \\
\text { files }\end{array}$ & $\begin{array}{l}\text { printer } \\
\text { /plotter } \\
\text { /HPGL file }\end{array}$ \\
\hline GISA & Interactive & $\begin{array}{l}\text { Manual iteration; } \\
\text { automated parameter } \\
\text { search }\end{array}$ & 2048 & $\begin{array}{l}\text { ASCII, } \\
\text { Canberra }\end{array}$ & $\begin{array}{l}\text { Independent } \\
\text { files }\end{array}$ & Screen only \\
\hline IBA & Interactive & Manual iteration & Unlimited & ASCII & $\begin{array}{l}\text { User input, } \\
\text { saved with } \\
\text { spectra in } \\
\text { GIF files. }\end{array}$ & $\begin{array}{l}\text { Publication } \\
\text { Quality }\end{array}$ \\
\hline $\begin{array}{l}\text { Particle } \\
\text { Solid Tools }\end{array}$ & $\begin{array}{l}\text { Interactive. } \\
\text { Tools are } \\
\text { callable } \\
\text { Mathematica } \\
\text { functions. }\end{array}$ & $\begin{array}{l}\text { RBS simulator returns } \\
\text { callable continuous } \\
\text { function. }\end{array}$ & $\begin{array}{l}\text { Simulated spectra } \\
\text { are continuous } \\
\text { functions. Data } \\
\text { arrays may be of } \\
\text { any length. }\end{array}$ & $\begin{array}{l}\text { Any data } \\
\text { format } \\
\text { compatible } \\
\text { with } \\
\text { Mathematica }\end{array}$ & $\begin{array}{l}\text { Stored } \\
\text { within the } \\
\text { spectrum } \\
\text { object. }\end{array}$ & $\begin{array}{l}\text { Uses } \\
\text { Mathematica }\end{array}$ \\
\hline PERM & Interactive & $\begin{array}{l}\text { Manual iteration, } \\
\text { automated profile search }\end{array}$ & 1024 & $\begin{array}{l}\text { ASCII, } \\
\text { PERM }\end{array}$ & $\begin{array}{l}\text { Stored with } \\
\text { spectra }\end{array}$ & Draft quality \\
\hline RBX & Interactive & Manual iteration & 4096 & $\begin{array}{l}\text { RUMP, } \\
\text { ASCII, SP4 }\end{array}$ & $\begin{array}{l}\text { Stored with } \\
\text { spectra }\end{array}$ & Draft quality \\
\hline RUMP & Interactive & $\begin{array}{l}\text { Manual iteration; } \\
\text { automated parameter } \\
\text { search }\end{array}$ & 16384 & $\begin{array}{l}\text { RUMP, } \\
\text { ASCII, user } \\
\text { DLL }\end{array}$ & $\begin{array}{l}\text { Stored with } \\
\text { spectra }\end{array}$ & $\begin{array}{l}\text { Publication } \\
\text { quality }\end{array}$ \\
\hline SIMNRA & Interactive & $\begin{array}{l}\text { Manual iteration; } \\
\text { automated parameter } \\
\text { search }\end{array}$ & 8192 & $\begin{array}{l}\text { ASCII, } \\
\text { Canberra, } \\
\text { RUMP, user } \\
\text { DLL }\end{array}$ & $\begin{array}{l}\text { Stored with } \\
\text { spectra }\end{array}$ & Draft quality \\
\hline WiNDF & $\begin{array}{l}\text { Batch } \\
\text { directed or } \\
\text { interactive }\end{array}$ & $\begin{array}{l}\text { Fully automated search; } \\
\text { manual iteration }\end{array}$ & 512 & $\begin{array}{l}\text { ASCII, } \\
\text { Canberra; } \\
\text { multiple } \\
\text { user } \\
\text { requested }\end{array}$ & $\begin{array}{l}\text { Independent } \\
\text { files; } \\
\text { optional } \\
\text { XML output } \\
\text { with all } \\
\text { information }\end{array}$ & Draft quality \\
\hline
\end{tabular}


TABLE 4. Fundamental databases used by analysis programs.
Analysis
Stopping powers
Cross Sections
Program

\begin{tabular}{|c|c|c|}
\hline $\begin{array}{l}\text { BEAM } \\
\text { EXPERT }\end{array}$ & Janni ${ }^{196}$, ZBL'$^{\prime} 85^{68}$, ZBL'98 $^{\prime}$ & Internal (modifiable) library of cross sections. \\
\hline BS1 & $\begin{array}{l}\text { Andersen and Ziegler }{ }^{197} \text {, user defined } \\
\text { correction per layer and ion. }\end{array}$ & User defined from file. \\
\hline DEPTH & ZBL'95 & User defined from file. \\
\hline DVBS & $\begin{array}{l}\text { ZBL'92 and user defined stored in data } \\
\text { tables. }\end{array}$ & User defined from file. \\
\hline GISA & $\begin{array}{l}\text { TRIM1991 or Ziegler and Chu }{ }^{198} \text {; } \\
\text { User defined correction per layer. }\end{array}$ & User defined from file. \\
\hline IBA & SRIM2000 & $\begin{array}{l}\text { Contains only } \mathrm{H}, \mathrm{He} \text { cross-sections for } \\
\text { NRA/ERDA. }\end{array}$ \\
\hline $\begin{array}{l}\text { Particle Solid } \\
\text { Tools }\end{array}$ & Default is ${ }^{199}$. User redefinable. & Default: Lenz-Jensen ${ }^{200}$, computed. \\
\hline PERM & ZBL'85 68 & Rutherford with L'Ecuyer's correction. \\
\hline RBX & $\begin{array}{l}\text { ZBL'95 With channeling correction } \\
\text { possible; User defined correction per layer. }\end{array}$ & $\begin{array}{l}\text { Internal (modifiable) library of cross sections; } \\
\text { external Cross-section Library Editor (import } \\
\text { Sigmabase R33 }{ }^{127,128} \text {; user defined). }\end{array}$ \\
\hline RUMP & $\begin{array}{l}\text { ZBL'92, KKKNS } 201 \\
\text { User defined compounds and databases, } \\
\text { user defined correction per layer or per } \\
\text { element. }\end{array}$ & SIGMABASE 127, 128 ; user defined. \\
\hline SIMNRA & $\begin{array}{l}\text { Either }{ }^{197} \text {, SRIM1997, SRIM2003, or } \\
\text { KKKNS } 201 \text {, user defined correction per } \\
\text { layer and ion. }\end{array}$ & SIGMABASE 127, 128 ; user defined. \\
\hline WinDF & $\begin{array}{l}\text { ZBL'85 } 68 \text { (SRIM2003 in non-commercial } \\
\text { versions), KKKNS } 201 \text { (Si), MSTAR }{ }^{113} \text {. } \\
\text { Ability to load other values; user defined } \\
\text { correction per ion/element. }\end{array}$ & User defined from file. \\
\hline
\end{tabular}


TABLE 5. Fundamental physics handled in the simulations.

\begin{tabular}{|c|c|c|c|c|c|c|c|}
\hline $\begin{array}{l}\text { Analysis } \\
\text { Program }\end{array}$ & $\begin{array}{c}\text { Isotope } \\
\text { Calculation } \\
\end{array}$ & $\begin{array}{l}\text { Screening } \\
\text { Calculation }\end{array}$ & $\begin{array}{l}\text { Stragglin } \\
\text { g models }\end{array}$ & $\begin{array}{l}\text { Plural } \\
\text { Scattering }\end{array}$ & $\begin{array}{l}\text { Multiple } \\
\text { Scattering } \\
\end{array}$ & $\begin{array}{l}\text { Geometric } \\
\text { Straggling } \\
\end{array}$ & Channeling \\
\hline $\begin{array}{l}\text { BEAM } \\
\text { EXPERT }\end{array}$ & $1)$ & $\begin{array}{l}\text { Energy/ } \\
\text { Angle - } \\
{[1]} \\
\text { empirical } \\
\text { formula } \\
\text { for HIBS }\end{array}$ & $\begin{array}{l}\text { [2] } \\
\text { with } \\
\text { fitting } \\
\text { factor }\end{array}$ & None & None & No & Defect Calculation \\
\hline BS1 & 2) & & {$[2]$} & None & None & No & No \\
\hline DEPTH & 2) & Yes & {$[3]$} & None & $\begin{array}{l}\text { Yes. } \\
\text { Pearson VII } \\
\text { distribution [11] }\end{array}$ & Yes & No \\
\hline DVBS & 3) & No & {$[4]$} & None & None & Yes & No \\
\hline GISA & 1) & $\begin{array}{l}\text { Energy/ } \\
\text { Angle - [5] }\end{array}$ & {$[2]+[6]$} & None & None & No & No \\
\hline IBA & 1) & $\begin{array}{l}\text { Yes, } \\
\text { SRIM } \\
\text { formalism }\end{array}$ & [7] & None & None & No & No \\
\hline $\begin{array}{l}\text { Particle } \\
\text { Solid } \\
\text { Tools }\end{array}$ & - & [8] & [9] & None & $\begin{array}{l}\text { Available, but } \\
\text { not part of RBS } \\
\text { simulation. }\end{array}$ & No & $\begin{array}{l}\text { Substrate } \\
\text { channeling } \\
\text { may be } \\
\text { parameterized in } \\
\text { the simulation to } \\
\text { facilitate fitting. }\end{array}$ \\
\hline PERM & 5) & $\begin{array}{l}\text { Energy } \\
\text { only - [10] }\end{array}$ & {$[2]$} & None & None & None & No \\
\hline $\mathrm{RBX}$ & 1) & Yes & {$[3]$} & None & $\begin{array}{l}\text { Yes (same model } \\
\text { as DEPTH) }\end{array}$ & Yes & $\begin{array}{l}\text { Defect Calculation } \\
\text { Simulation of } \\
\text { Channeled spectra }\end{array}$ \\
\hline RUMP & 1) & $\begin{array}{l}\text { Energy } \\
\text { only - [10] }\end{array}$ & {$[2]$} & None & None & No & No \\
\hline SIMNRA & 1) & $\begin{array}{l}\text { Energy/ } \\
\text { Angle - [5] }\end{array}$ & [7] & $\begin{array}{l}\text { Dual scattering } \\
\text { approx. (run } \\
\text { time option) }\end{array}$ & $\begin{array}{l}\text { Yes } \\
\text { (DEPTH model } \\
\text { approximated as } \\
\text { Gaussian) }\end{array}$ & Yes & No \\
\hline WinDF & 1) & $\begin{array}{l}\text { Energy/ } \\
\text { Angle - } \\
{[5] \text { and }} \\
{[10]}\end{array}$ & {$[3]$} & $\begin{array}{l}\text { Dual scattering } \\
\text { approx. (run } \\
\text { time option); } \\
\text { and ad-hoc } \\
\text { parameterizati } \\
\text { on (user } \\
\text { specified) }\end{array}$ & $\begin{array}{l}\text { Yes - Gaussian } \\
\text { approximation } \\
\text { from DEPTH } \\
\text { calculation }\end{array}$ & $\begin{array}{l}\text { Yes - from } \\
\text { DEPTH } \\
\text { calculation }\end{array}$ & No \\
\hline \multicolumn{4}{|c|}{$\begin{array}{l}\text { Comments: } \\
\text { 1) Specific isotopes and/or natural abundance } \\
\text { 2) Single isotope currently } \\
\text { 3) Yes, if provided external tables by users } \\
\text { 4) Default: All with natural abundances } \\
\text { 5) Natural or modified abundance }\end{array}$} & \multicolumn{4}{|c|}{$\begin{array}{l}\text { References: } \\
\text { [1] Huttel et al. }{ }^{202} \\
\text { [2] Bohr }{ }^{130} \\
\text { [3] Bohr }{ }^{130} \text {, Chu }{ }^{131} \text {, Yang et al. }{ }^{132} \text {, T } \\
\text { [4] Bohr }{ }^{130} \text {, Chu }{ }^{131} \text {, Yang et al. }{ }^{132} \\
\text { [5] Andersen et al } \\
\text { [6] Lindhard/Scharff }{ }^{203} \\
\text { [7] Chu }{ }^{131} \text { and Tschalär }{ }^{133,134,135} \\
\text { [8] Lenz-Jensen }{ }^{200} \\
\text { [9] Yang et al. }{ }^{132} \\
\text { [10] J. L'Ecuyer et al. }{ }^{116} \\
\text { [11] Pearson VII distribution }{ }^{93}\end{array}$} \\
\hline
\end{tabular}


TABLE 6. Experimental conditions and simulation capabilities.

\begin{tabular}{|c|c|c|c|c|c|c|c|}
\hline $\begin{array}{l}\text { Analysis } \\
\text { Program }\end{array}$ & $\begin{array}{l}\text { Incident } \\
\text { Ions }\end{array}$ & $\begin{array}{l}\text { Analytical } \\
\text { Techniques }\end{array}$ & $\begin{array}{l}\text { Scattering } \\
\text { Geometries }\end{array}$ & $\begin{array}{l}\text { Pileup } \\
\text { correction }\end{array}$ & $\begin{array}{l}\text { Detection } \\
\text { Systems } \\
\end{array}$ & Stopper Foils & $\begin{array}{l}\text { Energy } \\
\text { calibration }\end{array}$ \\
\hline $\begin{array}{l}\text { BEAM } \\
\text { EXPERT }\end{array}$ & All & $\begin{array}{l}\text { RBS, HIBS, } \\
\text { non-resonant } \\
\text { NRA }\end{array}$ & IBM & No & $\begin{array}{l}\text { Energy } \\
\text { dispersive }\end{array}$ & $\begin{array}{l}\text { Simulated; } \\
\text { Homogeneous } \\
\text { foils only }\end{array}$ & $\begin{array}{l}\text { Quadratic; } \\
\text { varying by ion } \\
\text { species }\end{array}$ \\
\hline BS1 & All & RBS, NRA & & No & $\begin{array}{l}\text { Energy } \\
\text { dispersive }\end{array}$ & $\begin{array}{l}\text { Simulated; } \\
\text { Homogeneous } \\
\text { foils only }\end{array}$ & Polynomial \\
\hline DEPTH & All & $\begin{array}{l}\text { RBS, ERDA, } \\
\text { NRA }\end{array}$ & $\begin{array}{l}\text { IBM, } \\
\text { Cornell }\end{array}$ & No & $\begin{array}{l}\text { Energy } \\
\text { dispersive } \\
\text { (magnetic } \\
\text { spectrograph } \\
\text { coming) }\end{array}$ & $\begin{array}{l}\text { Simulate; } \\
\text { including } \\
\text { inhomogeneities }\end{array}$ & Linear \\
\hline DVBS & All & RBS & $\begin{array}{l}\text { Cornell, } \\
\text { IBM, } \\
\text { General }\end{array}$ & No & $\begin{array}{l}\text { Energy } \\
\text { dispersive }\end{array}$ & $\mathrm{N} / \mathrm{A}$ & Polynomial \\
\hline GISA & All & RBS & IBM & No & $\begin{array}{l}\text { Energy } \\
\text { dispersive }\end{array}$ & N/A & Quadratic \\
\hline IBA & All & $\begin{array}{l}\text { RBS, ERDA, } \\
\text { NRA }\end{array}$ & General & No & $\begin{array}{l}\text { Energy } \\
\text { dispersive }\end{array}$ & $\begin{array}{l}\text { Simulated; } \\
\text { Homogeneous } \\
\text { foils only }\end{array}$ & Linear \\
\hline $\begin{array}{l}\text { Particle } \\
\text { Solid } \\
\text { Tools }\end{array}$ & All & $\begin{array}{l}\text { RBS and } \\
\text { medium } \\
\text { energy } \\
\text { backscattering. }\end{array}$ & General & No & $\begin{array}{l}\text { Default: energy } \\
\text { spectra. } \\
\text { Velocity and } \\
\text { time of flight } \\
\text { available. }\end{array}$ & N/A & $\begin{array}{l}\text { Arbitrary. User } \\
\text { defined. }\end{array}$ \\
\hline PERM & $\begin{array}{l}\mathrm{H}, \mathrm{D}, \mathrm{T}, \\
\mathrm{He}-4\end{array}$ & RBS & IBM & No & $\begin{array}{l}\text { Energy } \\
\text { dispersive }\end{array}$ & None & Linear \\
\hline $\mathrm{RBX}$ & All & $\begin{array}{l}\text { RBS, ERDA, } \\
\text { non-resonant } \\
\text { NRA }\end{array}$ & $\begin{array}{l}\text { IBM, } \\
\text { Cornell }\end{array}$ & Yes & $\begin{array}{l}\text { Energy } \\
\text { dispersive }\end{array}$ & $\begin{array}{l}\text { Simulated; } \\
\text { Homogeneous } \\
\text { foils only }\end{array}$ & Linear \\
\hline RUMP & All & RBS, ERDA & $\begin{array}{l}\text { Cornell, } \\
\text { IBM, } \\
\text { General }\end{array}$ & Yes & $\begin{array}{l}\text { Energy } \\
\text { dispersive, } \\
\text { partial TOF }\end{array}$ & $\begin{array}{l}\text { Simulated, or } \\
\text { from user } \\
\text { calibration }\end{array}$ & Linear \\
\hline SIMNRA & All & $\begin{array}{l}\text { RBS, ERDA, } \\
\text { non-resonant } \\
\text { NRA }\end{array}$ & General & No & $\begin{array}{l}\text { Energy } \\
\text { dispersive }\end{array}$ & $\begin{array}{l}\text { Simulated; } \\
\text { equivalent } \\
\text { treatment to } \\
\text { sample }\end{array}$ & $\begin{array}{l}\text { Quadratic; } \\
\text { varying by ion } \\
\text { species }\end{array}$ \\
\hline WiNDF & All & $\begin{array}{l}\text { RBS, ERDA, } \\
\text { non-resonant } \\
\text { NRA, NDP, } \\
\text { PIXE }\end{array}$ & $\begin{array}{l}\text { IBM, } \\
\text { Cornell }\end{array}$ & Yes & $\begin{array}{l}\text { Energy } \\
\text { dispersive }\end{array}$ & $\begin{array}{l}\text { Simulated; } \\
\text { Homogeneous } \\
\text { foils only }\end{array}$ & $\begin{array}{l}\text { Quadratic; } \\
\text { varying by ion } \\
\text { species }\end{array}$ \\
\hline
\end{tabular}


TABLE 7. Fitting capabilities (BS1, DEPTH, IBA and RBX have no fitting capabilities).

\begin{tabular}{|c|c|c|c|c|c|c|c|}
\hline $\begin{array}{l}\text { Analysis } \\
\text { Program }\end{array}$ & $\begin{array}{l}\text { Starting } \\
\text { conditions }\end{array}$ & $\begin{array}{l}\text { Optimization } \\
\text { method }\end{array}$ & Error estimation & $\begin{array}{l}\text { Statistics } \\
\text { used }\end{array}$ & $\begin{array}{l}\text { Searchable } \\
\text { experimental } \\
\text { parameters }\end{array}$ & $\begin{array}{l}\text { Auto- } \\
\text { refinement } \\
\text { of layers }\end{array}$ & Limitations \\
\hline $\begin{array}{l}\text { BEAM } \\
\text { EXPERT }\end{array}$ & $\begin{array}{l}\text { Elements only } \\
\text { or guess; } \\
\text { elemental } \\
\text { search also } \\
\text { possible }\end{array}$ & $\begin{array}{l}\text { P'itiev } \\
\text { reduction }\end{array}$ & $\begin{array}{l}\text { Creation the } \\
\text { variance- } \\
\text { covariance } \\
\text { matrix of the } \\
\text { solution error }\end{array}$ & Poisson & $\mathrm{E}_{\mathrm{cal}}$, charge & No & $\begin{array}{l}\text { Method considers } \\
\text { all parameters } \\
\text { variable }\end{array}$ \\
\hline DVBS & $\begin{array}{l}\text { Build up } \\
\text { concentration } \\
\text { profile based } \\
\text { on displayed } \\
\text { element edges } \\
\text { in calibration } \\
\text { module. }\end{array}$ & $\begin{array}{l}\chi^{2} \\
\text { minimization }\end{array}$ & $\chi^{2}$ & Gaussian & $\begin{array}{l}\mathrm{E}_{\text {cal, }} \text {, charge, } \\
\text { scattering } \\
\text { angles }\end{array}$ & No & $\begin{array}{l}\text { Autofit capabilities } \\
\text { for just one partial } \\
\text { spectrum in } \\
\text { concentration } \\
\text { profile with more } \\
\text { elements in a time. }\end{array}$ \\
\hline GISA & $\begin{array}{l}\text { Reasonable } \\
\text { guess }\end{array}$ & $\begin{array}{l}\chi^{2} \\
\text { minimization }\end{array}$ & None returned & & None & No & $\begin{array}{l}\text { One layer } \\
\text { at a time }\end{array}$ \\
\hline $\begin{array}{l}\text { Particle } \\
\text { Solid } \\
\text { Tools }\end{array}$ & $\begin{array}{l}\text { Reasonable } \\
\text { guess. }\end{array}$ & $\begin{array}{l}\text { Levenberg- } \\
\text { Marquardt }\end{array}$ & $\begin{array}{l}\text { Full covariance } \\
\text { matrix }\end{array}$ & $\begin{array}{l}\text { User } \\
\text { definable. } \\
\text { Default, } \\
\text { Poisson. }\end{array}$ & $\begin{array}{l}\text { In principle } \\
\text { possible } \\
\text { within } \\
\text { Mathematica }\end{array}$ & N/A & $\begin{array}{l}\text { Any continuous } \\
\text { parameters of the } \\
\text { user's model may } \\
\text { be fit. }\end{array}$ \\
\hline PERM & $\begin{array}{l}\text { Reasonable } \\
\text { guess }\end{array}$ & $\begin{array}{l}\text { "Profile } \\
\text { reconstitution" } \\
\text { method }\end{array}$ & N/A & Poisson & $\begin{array}{l}\mathrm{E}_{\text {cal }} \text {, charge, } \\
\text { surface } \\
\text { potential } \\
\text { (insulators) }\end{array}$ & No & N/A \\
\hline RUMP & $\begin{array}{l}\text { Reasonable } \\
\text { guess }\end{array}$ & $\begin{array}{l}\text { Marquart } \\
\text { search }\end{array}$ & $\begin{array}{l}\text { Curvature of chi- } \\
\text { square matrix; } \\
\text { full correlation } \\
\text { of error } \\
\text { sensitivities } \\
\text { (intrinsic in } \\
\text { search method) }\end{array}$ & Poisson & $\begin{array}{l}E_{0}, E_{\text {cal }}, \\
\text { charge, } \\
\text { current, } \\
\theta, \Phi, \varphi\end{array}$ & No & $\begin{array}{l}\text { No internal limit, } \\
\text { practical of } 30 \\
\text { parameters at a } \\
\text { time }\end{array}$ \\
\hline SIMNRA & $\begin{array}{l}\text { Reasonable } \\
\text { guess }\end{array}$ & $\begin{array}{l}\text { Simplex } \\
\text { search }\end{array}$ & $\begin{array}{l}\text { Additional } \\
\text { search to } \\
\text { determine } \\
\text { curvature near } \\
\text { best fit } \\
\text { (comparable to } \\
\text { fit time) }\end{array}$ & $\begin{array}{l}\text { Poisson } \\
<4 ; \\
\text { Gaussian }\end{array}$ & $\begin{array}{l}E_{\text {cal, }} \\
\text { charge }\end{array}$ & No & $\begin{array}{l}\text { One layer at a time, } \\
\text { all characteristics }\end{array}$ \\
\hline WiNDF & $\begin{array}{l}\text { Elements only } \\
\text { or guess; } \\
\text { elemental } \\
\text { search also } \\
\text { possible }\end{array}$ & $\begin{array}{l}\text { Simulated } \\
\text { annealing plus } \\
\text { grid search }\end{array}$ & $\begin{array}{l}\text { Bayesian } \\
\text { inference with } \\
\text { Markov chain } \\
\text { Monte Carlo } \\
\text { integration (time } \\
\text { intensive) }\end{array}$ & $\begin{array}{l}\text { ad-hoc in } \\
\text { SA; } \\
\text { Poisson in } \\
\text { BI }\end{array}$ & $\mathrm{E}_{\mathrm{cal}}$, charge & Yes & $\begin{array}{l}\text { Method considers } \\
\text { all parameters } \\
\text { variable }\end{array}$ \\
\hline
\end{tabular}


TABLE 8. Sample definition and complexity handled.

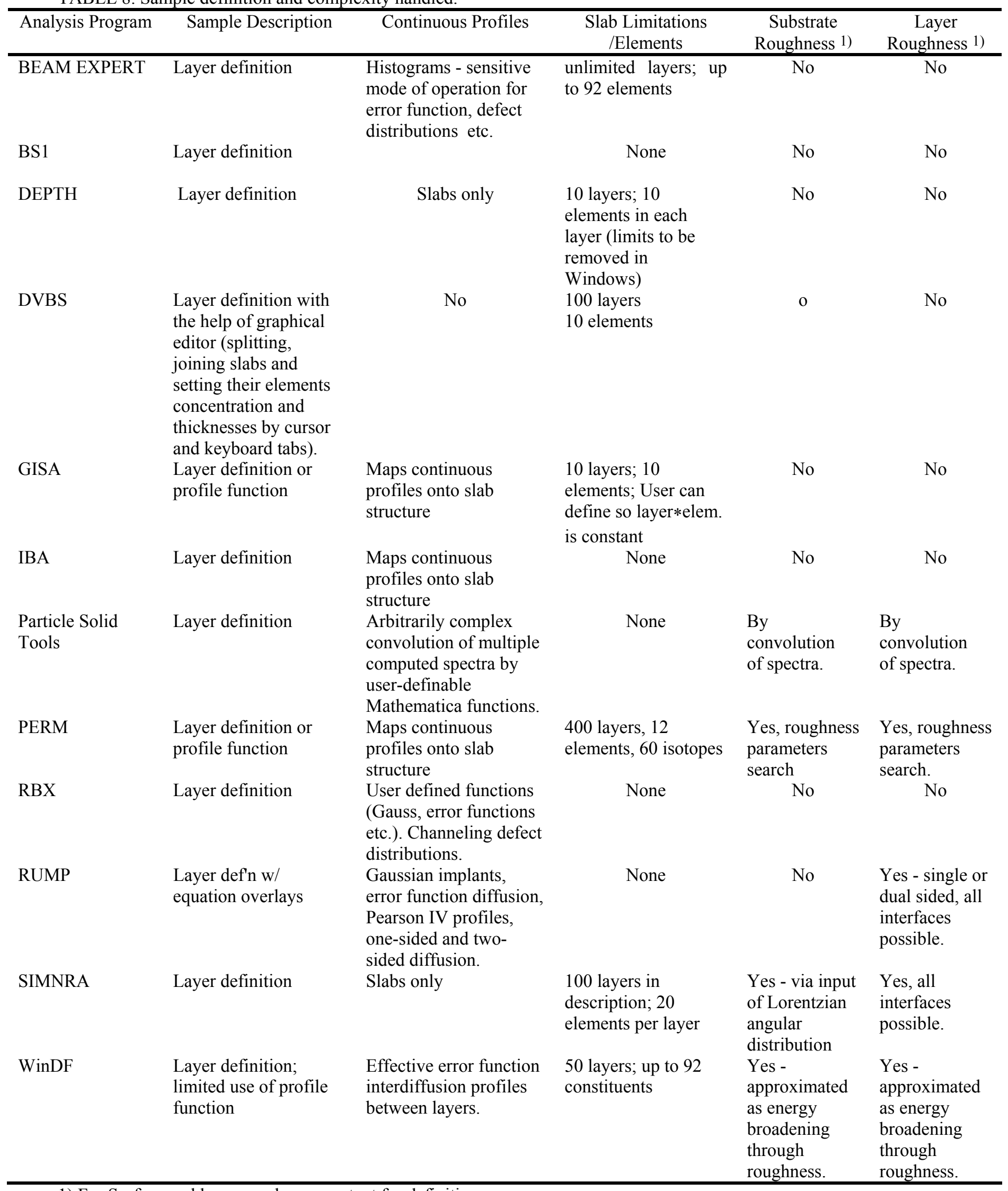

1) For Surface and layer roughness see text for definition. 


\section{References}

${ }^{1}$ D. Arnold, M. Blaauw, S. Fazinic and V. P. Kolotov, Nucl. Instr. and Meth. A536 (2005) 196-210; and Intercomparison of gamma ray analysis software packages, IAEATECDOC-1011 (IAEA, Vienna, 1998) http://wwwpub.iaea.org/MTCD/publications/tecdocs.asp.

${ }^{2}$ M. Blaauw, E. García-Toraño, S. Woods and S. Fazinić, Nucl. Instr. and Meth. A 428, (1999) 317; and Intercomparison of alpha particle spectrometry software packages, IAEA-TECDOC-1104(IAEA, $\quad$ Vienna, $\quad$ 1999), pub.iaea.org/MTCD/publications/tecdocs.asp.

${ }^{3}$ M. Blaauw, J.L. Campbell, S. Fazinić, M. Jakšić, I. Orlic, P. Van Espen, Nucl. Instr. and Meth. B189 (2002) 113.

${ }^{4}$ Status of software for Ion Beam Analysis in Materials Development, NAPC/PS/2002/F1.TM - 25886, (IAEA, Vienna 2003).

${ }^{5}$ The INSPEC database, produced by the Institution of Electrical Engineers, Version 5.03 Build 20030416 C 1997-2003 Ovid Technologies; http://web5.silverplatter.com.

${ }^{6}$ E. Rauhala, in Elemental Analysis by Particle Accelerators, ed. Z.B. Alfassi, (CRC Press, 1992), pp. 179.

${ }^{7}$ J. Saarilahti and E. Rauhala, Nucl. Instr. and Meth. B64 (1992) 734.

${ }^{8}$ G. Vízkelethy, Nucl. Instr. and Meth. B89 (1994) 122.

${ }^{9}$ E. Kótai, Nucl. Instr. and Meth. B85 (1994) 588.

${ }^{10}$ C. Jeynes, N.P. Barradas, P.K. Marriott, G. Boudreault, M. Jenkin, E. Wendler and R.P. Webb, J. Phys. D: Appl. Phys. 36 (2003) R97.

${ }^{11}$ J.F. Ziegler, J.E.E. Baglin, J. Appl. Phys. 42 (1971) 2031.

${ }^{12}$ A. Weber, H. Mommsen, W. Sarter, A. Weller, Nucl. Instr. and Meth. 198 (1982) 527. 
${ }^{13}$ A. Weber and H. Mommsen, Nucl. Instr. and Meth. 204 (1983) 559.

${ }^{14}$ A. Weber, Q. Fazly, H. Mommsen, Nucl. Instr. and Meth. B4 (1984) 79.

${ }^{15}$ R.D. Edge and U. Bill, Nucl. Instr. and Meth. 168 (1980) 157.

${ }^{16}$ R.D. Edge, IEEE Transactions on Nuclear Science NS-30B (1983) 1685.

${ }^{17}$ E. Rauhala, J. Appl. Phys. 62 (1987) 2140.

${ }^{18}$ P.F.A. Alkemade, F.H. Habraken and W.F. van der Weg, Nucl. Instr. and Meth. B45 (1990) 139.

${ }^{19}$ J.W. Butler, Nucl. Instr. and Meth. B45 (1990) 160.

${ }^{20}$ Z.L. Liau, Appl. Phys. Lett. 36 (1979) 51.

${ }^{21}$ M.B. Lewis, Nucl. Instr. and Meth. 190 (1981) 605.

${ }^{22}$ J. Richards, Nucl. Instr. and Meth. 152 (1978) 585.

${ }^{23}$ D.J. O’Connor and Tan Chunyu, Nucl. Instr. and Meth. B36 (1989) 178 .

${ }^{24}$ Q. Yang and D.J. O’Connor, Nucl. Instr. and Meth. B67 (1992) 98.

${ }^{25}$ Q. Yand and D.J. O’Connor, Z. Fang, T.R. Ophel, H.J. Hay, T.E. Jackman, Nucl. Instr. and Meth. B74 (1993) 431.

${ }^{26}$ I. Vickridge and G. Amsel, Nucl. Instr. and Meth. B45 (1990) 6.

${ }^{27}$ G. Amsel and I. Vickridge, Nucl. Instr. and Meth. B45 (1990) 12.

${ }^{28}$ V. Hnatowicz, V. Havránek and J. Kvítek, Computer Phys. Comm. 72 (1992) 295.

${ }^{29}$ P. Børgesen, R. Behrisch and B.M.U. Scherzer, Appl. Phys. A27 (1982) 183.

${ }^{30}$ I. Petrov, M. Braun, T. Fried and H. Sätherblom, J. Appl. Phys. 54 (1983) 1358.

${ }^{31}$ J.M. Eridon and G.S. Was, Nucl. Instr. and Meth. B12 (1985) 505.

${ }^{32}$ W. Dachun and M. Xianren, Nucl. Instr. and Meth. B15 (1986) 265.

${ }^{33}$ W.Z. Li and Z. Al-Tamini, Nucl. Instr. and Meth. B15 (1986) 241. 
${ }^{34}$ Qi-Chu Zhang, P. McMillan and J.C. Kelly, Radiation Effects and Defects in solids 114 (1990) 115.

${ }^{35}$ R.D. Edge, Nucl. Instr. and Meth. B35 (1988) 309.

${ }^{36}$ K. Michealian and E. Andrade, Nucl. Instr. and Meth. B74 (1993) 443.

${ }^{37}$ D.I. Kogan, A.M. Kazancev, and L.E. Kuzmin, Nucl. Instr. and Meth. B88 (1994) 495.

${ }^{38}$ J.F. Ziegler, R.F. Lever, and J.K. Hirvonen, in Ion Beam Surface Layer Analysis, eds. O. Meyer, G. Linker and F. Käppeler (Plenum, New York, 1976) Vol. 1 p. 163.

${ }^{39}$ P.A. Saunders and J.F. Ziegler, Nucl. Instr. and Meth. 218 (1983) 67.

${ }^{40}$ J.F. Ziegler, Nucl. Instr. and Meth. B136-138 (1998) 141.

${ }^{41}$ W.K. Chu, J.W. Mayer, and M.-A. Nicolet, Backscattering Spectrometry (Academic Press, New York, 1978).

${ }^{42}$ P. Müller, W. Szymczak and G. Ischenko, Nucl. Instr. and Meth. 149 (1978) 239.

${ }^{43}$ L.C. Northcliffe and R.F. Schilling, Nucl. Data Tables A7 (1970) 233.

${ }^{44}$ T.L.M. Marcuso, S.J. Rothman, L.J. Nowicki and P. Baldo, Nucl. Instr. and Meth. 211 (1983) 227.

${ }^{45}$ E. Rauhala, J. Appl. Phys. 56 (1984) 3324.

${ }^{46}$ J.C.B. Simpson and L.G. Earwaker, Vacuum, 34 (1984) 899.

${ }^{47}$ J.C.B. Simpson and L.G. Earwaker, Nucl. Instr. and Meth. B15 (1986) 502.

${ }^{48}$ Y. Kido and Y. Oso, Nucl. Instr. and Meth. B9 (1985) 291.

${ }^{49}$ L.R. Doolittle, Nucl. Instr. and Meth. B9 (1985) 344.

${ }^{50}$ L.R. Doolittle, Nucl. Instr. and Meth. B15 (1986) 227.

${ }^{51}$ J. M. Knox, R.J. McLeod, D.R. Mayo and X. Qian, Nucl. Instr. and Meth. B45 (1990) 26.

${ }^{52}$ A. Climent-Font, U. Wätjen and H. Bax, Nucl. Instr. and Meth. B71 (1992) 81.

${ }^{53}$ J.W. Butler, Nucl. Instr. and Meth. B15 (1986) 232. 
${ }^{54}$ J.W. Butler, Nucl. Instr. and Meth. B24/25 (1987) 1039.

${ }^{55}$ E. Rauhala, Nucl. Instr. and Meth. B40/41 (1989) 790.

${ }^{56}$ G. Vizkelethy, Nucl. Instr. and Meth. B45 (1990) 1.

${ }^{57}$ X.S. Guo, W.A. Lanford, and K.P. Rodbell, Nucl. Instr. and Meth. B45 (1990) 157.

${ }^{58}$ Y. Serruys, Nucl. Instr. and Meth. B44 (1990) 473.

${ }^{59}$ Y. Serruys, Nucl. Instr. and Meth. B61 (1991) 221.

${ }^{60}$ Y. Serruys, J. Tirira, P. Calmon, Nucl. Instr. and Meth. B74 (1993) 565.

${ }^{61}$ J. Saarilahti, E. Rauhala, Nucl. Instr. and Meth. B64 (1992) 734. (same as 7)

${ }^{62}$ V. Hnatowicz, V. Havránek and J. Kvítek, Computer Physics Communications 72 (1992) 295. (same as 28)

${ }^{63}$ Jiang Weilin, Zhai Guangnian, Ren Mengmei and Zhu Peiran, Chinese Phys. Lett. 9 (1992) 229.

${ }^{64}$ N.D. Skelland, Nucl. Instr. and Meth. B84 (1994) 361.

${ }^{65}$ B. Bohác, D.M. Shirokov, Nucl. Instr. and Meth. B84 (1994) 497.

${ }^{66}$ B. Rajchel, Nucl. Instr. and Meth. B113 (1996) 300.

${ }^{67}$ G. Kuri, K. Sekar, P.V. Satyam and D.P. Mahapatra, Indian J. Phys. 70A (1996) 465.

${ }^{68}$ J. F. Ziegler, J. P. Biersack, and U. Littmark, Stopping and Ranges of Ions in Solids (Pergamon, New York, 1985).

${ }^{69}$ T. Nishimura, Y. Kido, M. Badaye, Y. Yoshida, F. Wang, T. Morishita and M. Kumagai, J. Appl. Phys. 79 (1996) 14.

${ }^{70}$ N. Marin, Y. Serruys, P. Calmon, Nucl. Instr. and Meth. B108 (1996) 179.

${ }^{71}$ E. Kótai, AIP Proceedings CP392 (1997) 631.

${ }^{72}$ R.A. Weller, AIP Proceedings CP475 (1999) 596.

73 J.P. Stoquert, T. Szörenyi, Phys. Rev. B 66 (2002) 144108. 
${ }^{74}$ N.P. Barradas, C. Jeynes, and R.P. Webb, Appl. Phys. Lett. 71 (1997) 291.

${ }^{75}$ N.P. Barradas, P.K. Marriott, C. Jeynes, R.P. Webb, Nucl. Instr. and Meth. B136-138 (1998) 1157.

${ }^{76}$ S. Kirkpatrik, C.D. Gelatt and M.P. Vecchi, Science 220 (1983) 671.

77 E. Aarts and J. Korst, Simulated Annelaing and Boltzmann Machines: A Stochastic Approach to Combinatorial Optimization and Neural Computing (Wiley, Chichester, 1989).

${ }^{78}$ N.P. Barradas and A.Vieira, Phys. Rev. E62 (2000) 5818.

${ }^{79}$ M. Mayer, Technical Report IPP9/113, Max-Planck-Institut für Plasmaphysik, Garching, Germany (1997).

${ }^{80}$ M. Mayer, AIP Proceedings CP475 (1999) 541.

${ }^{81}$ M. Mayer, Nucl. Instr. and Meth. B194 (2002) 177.

${ }^{82}$ M. Tosaki, S. Ito and N. Maeda, Nucl. Instr. and Meth. B168 (2000) 543.

${ }^{83}$ K. Oxorn, S.C. Gujrathi, S. Bultena, L. Cliche and J. Miskin, Nucl. Instr. and Meth. B45 (1990) 166.

84 W.M. ArnoldBik, F. H. P. M. Habraken, Rep. Prog. Phys. 56 (1993) 859.

85 A. Bergmaier, G. Dollinger, C.M. Frey, Nucl. Instrum. Methods B99 (1995) 488.

86 F. Schiettekatte, G. G. Ross, AIP Press CP392 (1997) 711.

${ }^{87}$ S. Grigull, U. Kreissig, H, Huber, W. Assmann, Nucl. Instr. and Meth. B132 (1997) 709.

${ }^{88}$ C. Spaeth, F. Richter, S. Grigull, U. Kreissig, Nucl. Instr. and Meth. B140 (1998) 243.

${ }^{89}$ L. Persson, H. Whitlow, M.El Bouanani, M. Hult, A.Andersson, I.F. Rubb, D.D. Cohen, N. Dytlewski, P.N. Johnston, S.R. Walker, C. Zaring, and M. Östling, Nucl. Instr. and Meth. B179 (2001) 403. 
${ }^{90}$ R.D. Verda, C.J. Maggiore, J.R. Tesmer, A. Misra, T. Hoechbauer, M. Nastasi and R.W. Bower, Nucl. Instr. and Meth. B183 (2001) 401.

${ }^{91}$ I.M. Yesil, W. Assmann, H. Huber, K.E.G. Löbner, Nucl. Instr. and Meth. B136-138 (1998) 623.

${ }^{92}$ R. Behrisch, S. Grigull, U. Kreissig, and R. Grötzschel, Nucl. Instr. and Meth. B136-138 (1998) 628.

${ }^{93}$ E. Szilágyi, F. Pászti, G. Amsel, Nucl. Instr. and Meth. B100 (1995) 103.

${ }^{94}$ E. Szilágyi, Nucl. Instr. and Meth. B161 - 163 (2000) 37.

${ }^{95}$ E. Szilágyi, Nucl. Instr. and Meth. B183 (2001) 25.

${ }^{96}$ L.S. Wielunski, E. Szilágyi and G.L. Harding, Nucl. Instr. and Meth. B136-138 (1998) 713.

${ }^{97}$ G. Dollinger, C.M. Frey, A. Bergmaier, T. Faestermann, Nucl. Instr. and Meth. B 136-138 (1998) 603.

${ }^{98}$ V.S. Shorin and A.N. Sosnin, Nucl. Instr. and Meth. B72 (1992) 452.

${ }^{99}$ E. Steinbauer, P. Bauer and J. Biersack, Nucl. Instr. and Meth. B45 (1990) 171.

${ }^{100}$ J.P. Biersack, E. Steinbauer and P. Bauer, Nucl. Instr. and Meth. B61 (1991) 77 .

${ }^{101}$ P. Bauer, E. Steinbauer and J.P. Biersack, Nucl. Instr. and Meth. B64 (1992) 711.

${ }^{102}$ M.M. Li and D.J. O’Connor, Nucl. Instr. and Meth. B149 (1999) 460.

${ }^{103}$ W. Eckstein and M. Mayer, Nucl. Instr. and Meth. B153 (1999) 337.

${ }^{104}$ P. Pusa, T. Ahlgren, E. Rauhala, Nucl. Instr. and Meth. B219-220 (2004) 95.

105 T. Sajavaara, K. Arstila, A. Laakso and J. Keinonen, Nucl. Instr. and Meth. B161-163 (2000) 235 .

${ }^{106}$ K. Arstila, T. Sajavaara and J. Keinonen, Nucl. Instr. and Meth. B174 (2001) 163.

${ }^{107}$ P.N. Johnston, R.D. Franich, I.F. Bubb, M.El Bouanani, D.D. Cohen, N. Dytlewski and R. Siegele, Nucl. Instr. and Meth. B161-163 (2000) 314. 
${ }^{108}$ R.D. Franich, P.N. Johnston, I.F. Bubb, N. Dytlewski, and D.D. Cohen, Nucl. Instr. and Meth. B190 (2002) 252.

${ }^{109}$ Handbook of Modern Ion Beam Materials Analysis, edited by JR Tesmer and M. Nastasi (Materials Research Society, Pittsburgh, 1995).

${ }^{110}$ www.SRIM.org; J.F. Ziegler, Nucl. Instr. and Meth. B219-220 (2004) 1027.

111 ICRU Report 49, International Commission on Radiation Units and Measurements, Bethesda, MD, USA, 1993.

${ }^{112}$ Available from http://physics.nist.gov/PhysRefData/Star/Text/contents.html

${ }^{113}$ H. Paul, A. Schinner, Nucl. Instr. and Meth. B209 (2003) 252.

114 T. D. M. Weijers, B. C. Duck, D.J. O’Connor, Nucl. Instrum. Methods B 215 (2004) 35.

115 G. Konac, S. Kalbitzer, Ch. Klatt, D. Niemann, R. Stoll, Nucl. Instrum. Methods B136$138(1998) 159$.

${ }^{116}$ J. L'Ecuyer, J.A. Davies, N. Matsunami, Nucl. Instr. and Meth. 160 (1979) 337.

${ }^{117}$ H.H. Andersen, F. Besenbacher, P. Loftager and W. Möller, Phys. Rev. A 21 (1980) 1891.

${ }^{118}$ M.H. Mendenhall and R.A. Weller, Nucl. Instr. and Meth. B58 (1991) 11; Nucl. Instr. and Meth. B58 (1994) 5.

${ }^{119}$ M.H. Mendenhall and R.A. Weller, Nucl. Instr. and Meth. B227 (2005) 420.

${ }^{120}$ A.F.Gurbich, Nucl. Instr. and Meth. B145 (1998) 578.

${ }^{121}$ A.F. Gurbich, Nucl. Instr. and Meth. B152 (1999) 403.

${ }^{122}$ M.J.F. Healy, A.F.Gurbich, Nucl. Instr. and Meth. B161 (2000) 136.

${ }^{123}$ S.K. Kim, H.D. Choi, Nucl. Instr. and Meth. B174 (2001) 33.

${ }^{124}$ A. Nurmela, P. Pusa, E. Rauhala, J. Räisänen, J. Appl. Phys. 91 (2002) 2438.

${ }^{125}$ P. Pusa, E. Rauhala, T. Alanko, J. Räisänen, J. Appl. Phys. 93 (2003) 6370.

${ }^{126} \mathrm{http}: / /$ www.physics.isu.edu/sigmabase/programs/nrabase2.html 
${ }^{127}$ http://www.mfa.kfki.hu/sigmabase/

${ }^{128} \mathrm{http}: / /$ www-nds.iaea.org/ibandl/

129 A. F. Gurbich, N. P. Barradas, C. Jeynes, E. Wendler, Nucl. Instrum. Methods B190 (2002) 237.

${ }^{130}$ N. Bohr, Math. Phys. Medd. Vid. Selsk. 18 (8) (1948).

${ }^{131}$ W.K. Chu, Phys. Rev. A 13 (1976) 2057.

${ }^{132}$ Q. Yang, D.J. O’Connor, Zhonglie Wang, Nucl. Instr. and Meth. B61 (1991) 149.

${ }^{133}$ C. Tschalär, Nucl. Instr. Meth. 61 (1968) 141.

${ }^{134}$ C. Tschalär, Nucl. Instr. and Meth. 64 (1968) 237.

${ }^{135}$ C. Tschalär, H.D. Maccabee, Phys.Rev. B1 (1970) 2863.

${ }^{136}$ R. Fischer, M. Mayer, W. von der Linden, V. Dose, Phys. Rev. E55 (1997) 1.

${ }^{137}$ P. Sigmund, K. B. Winterbon, Nucl. Instrum. Meth. 119 (1974) 541.

${ }^{138}$ G. Amsel, G. Battistig, A. L’Hoir, Nucl. Instr. and Meth. B201 (2003) 325.

139 B. M. U. Scherzer, P. Børgesen, M.-A. Nicolet, J. W. Mayer, in: Ion Beam Surface Layer Analysis ed. O. Meyer, G. Linker, F. Käppeler (Plenum Press, New York, 1976).

${ }^{140}$ F. Repplinger, J. P. Stoquert, P. Siffert, Nucl. Instr. and Meth. B80/81 (1993) 24.

${ }^{141}$ N.P. Barradas, Nucl. Instr. and Meth. B225 (2004) 318

${ }^{142}$ V. Ya. Chumanov, Sh. Z. Izmailov, G. P. Pokhil, E. I. Sirotinin, A. F. Tulinov, Phys. Status Solidi A53 (1979) 51.

${ }^{143}$ E. I. Sirotinin, A. F. Tulinov, V. A. Khodyrev, V. N. Mizgulin, Nucl. Instr. and Meth. B4 (1984) 337.

${ }^{144}$ D. Dieumegard, D. Dubreuil and G. Amsel, Nucl. Instr. and Meth. 166 (1979) 431

${ }^{145}$ R. Günzler, V. Schüle, G. Seeliger, M. Weiser, K. Böhringer, S. Kalbitzer, J. Kemmer, Nucl. Instr. and Meth. B35 (1988) 522. 
${ }^{146}$ G. Amsel, E. Girard, G. Vizkelethy, G. Battistig, Y. Girard, E. Szilágyi, Nucl. Instr. and Meth. B64 (1992) 811.

${ }^{147}$ K.M. Langen, P.J. Binns, A.J. Lennox, T.K. Kroc, P.M. DeLuca Jr. , Nucl. Instr. and Meth. A484 (2002) 595.

${ }^{148}$ L. Wielopolski and R.P. Gardner, Nucl. Instr. Meth. 133 (1976) 303

${ }^{149}$ D. Cano-Ott, J.L. Tain, A. Gadea, B. Rubio, L. Batist, M. Karny, and E. Roeckl, Nucl. Instr. Meth. A430 (1999) 488

${ }^{150}$ C. Jeynes, Z.H. Jafri, R.P. Webb, M.J. Ashwin, A.C. Kimber, Surf. Interface Anal. 25 (1997) 254 .

${ }^{151}$ E. C. Finch, A. L. Rodgers, Nucl. Instr. and Meth. 113 (1973) 29.

${ }^{152}$ E. C. Finch, M. Ashgar, M. Forte, Nucl. Instr. and Meth. 163 (1979) 467.

${ }^{153}$ G. Amsel, F. Pászti, E. Szilágyi, J. Gyulai, Nucl. Instr. and Meth. B 63 (1992) 421.

${ }^{154}$ W.N. Lennard, H. Geissel, K. B. Winterbon, D. Phillips, T. K. Alexander, J. S. Forster, Nucl. Instr. and Meth. A248 (1986) 454.

${ }^{155}$ W.N. Lennard, H. Xia, J.K. Kim, Nucl. Instr. and Meth. B215 (2004) 297.

${ }^{156}$ C. Pascual-Izarra, G. Garcia, Nucl. Instr. and Meth. B225 (2004) 383.

157 R. S. Blewer, in: Ion Beam Surface Layer Analysis ed. O. Meyer, G. Linker, F. Käppeler (Plenum Press, New York, 1976).

158 L. Varga, Nucl. Instr. and Meth. B17 (1986) 260.

159 S. I. Bazhukov, A. V. Kibardin, T. M. Pyatkova, Nucl. Instr. and Meth. B58 (1991) 242.

${ }^{160}$ N.P. Barradas, J.C. Soares, M.F. da Silva, F. Pászti, and E. Szilágyi, Nucl. Instr. and Meth. B94 (1994) 266.

161 A. R. Knudson, Nucl. Instr. and Meth. 168 (1980) 163.

162 J.R. Bird, D.D. Cohen, G.B. Smith, P. Hillery, Nucl. Instr. and Meth. 218 (1983) 53. 
163 C. P. Hobbs, J. W. McMillan, D. W. Palmer, Nucl. Instr. and Meth. B30 (1988) 342.

${ }^{164}$ M. Wüest, P. Bochsler, Nucl. Instr. and Meth. B71 (1992) 314.

${ }^{165}$ P.R. Berning, A. Niiler, Nucl. Instr. and Meth. B73 (1993) 178.

166 Y. Itoh, T. Maeda, T. Nakajima, A. Kitamura, N. Ogiwara, M. Saidoh, Nucl. Instr. and Meth. B117 (1996) 161.

${ }^{167}$ H. Metzner, M. Gossla, Th. Hahn, Nucl. Instr. and Meth. B124 (1997) 567.

168 A. Kitamura, T. Tamai, A. Taniike, Y. Furuyama, T. Maeda, N. Ogiwara, M. Saidoh, Nucl. Instr. and Meth. B134 (1998) 98.

${ }^{169}$ J. Slotte, A. Laakso, T. Ahlgren, E. Rauhala, R. Salonen, J. Räisänen, A. Simon, I, Uzonyi, Á.Z. Kiss, E. Somorjai, J. Appl. Phys. 87 (2000) 140.

${ }^{170}$ T. Sajavaara, K. Arstila, A. Laakso, J. Keinonen, Nucl. Instr. and Meth. B161-163 (2000) 235.

171 N. P. Barradas, J. Phys. D: Appl. Phys. 34 (2001) 2109.

172 S. Lindner, W. Bohne, A. Jäger-Waldau, M.Ch. Lux-Steiner, J. Rörich, G. Vogl, Thin Solid Films 403-404 (2002) 432.

${ }^{173}$ W. Bohne, S. Lindner, J. Rörich, Nucl. Instr. and Meth. B188 (2002) 55.

${ }^{174}$ A. Simon, Z. Kántor, Nucl. Instr. and Meth. B190 (2002) 351.

175 N. P. Barradas, E Alves, S. Pereira, V. V. Shvartsman, A. L. Kholkin, E. Pereira, K. P. O’Donnell, C. Liu, C. J. Deatcher I. M. Watson, M. Mayer, Nucl. Instr. and Meth. B217 (2004) 479 .

${ }^{176}$ M. Mayer, R. Fischer, S. Lindig, U. von Toussaint, R.W. Stark, and V. Dose, Nucl. Instr. Meth. B228 (2005) 349

${ }^{177}$ C.J. Tavers, L. Rebouta, E.J. Alves, B. Almeida, J. Bessa e Sousa, M.F. da Silva, J.C. Soares, Nucl. Instr. Meth. B 136-138 (1998) 278. 
${ }^{178}$ G. Amsel, E. d'Artemare, G. Battistig, V. Morazzani, C. Ortega, Nucl. Instr. Meth. B 122 (1997) 99.

179 E. Szilágyi, Z. Hajnal, F. Pászti, O. Buiu, G. Graciun, C. Cobianu, C. Savaniu, É. Vázsonyi, Mat. Sci. Forum, 248-249 (1997) 373.

${ }^{180}$ Z. Hajnal, E. Szilágyi, F. Pászti, G. Battistig, Nucl. Instr. Meth. B 118 (1996) 617.

${ }^{181}$ F. Pászti, G. Battistig, Phys. Stat. Sol. (a) 182 (2000) 271 - 278.

${ }^{182}$ E. Kótai, Nucl. Instr. Meth. B 148 (1999) 172 - 175.

${ }^{183}$ Z. Zolnai, N.Q. Khanh, T. Lohner, A. Ster, E. Kótai, I. Vickridge, J. Gyulai, Mater. Sci. Forum 433-4 (2003) 645 - 648.

${ }^{184}$ P. J. M. Smulders and D. O. Boerma, Nucl. Instr. and Meth. B29 (1987) 471.

${ }^{185}$ A. Kling, Nucl. Instr. and Meth. B102 (1995) 141.

${ }^{186}$ E. Edelmann, K. Arstila, J. Keinonen, Nucl. Instr. and Meth. B, in press

${ }^{187}$ N.P. Barradas, C. Jeynes, M. Jenkin, P.K. Marriott, Thin Solid Films 343-344 (1999) 31.

${ }^{188}$ U. von Toussaint, K. Krieger, R. Fischer and V. Dose, in: Maximum Entropy and Bayesian Methods, W. von der Linden et al. (eds.), Kluwer Academic Publishers, 1999.

${ }^{189}$ U. von Toussaint, R. Fischer, K. Krieger and V. Dose, New Journal of Physics 1 (1999) 11.1

${ }^{190}$ R. Fischer, Anal. Bioanal. Chem. 374 (2002) 619

${ }^{191}$ N.P. Barradas, C. Jeynes, R.P. Webb, U. Kreissig, R. Grötzschel, Nucl. Instr. and Meth. B149 (1999) 233.

192 N.P. Barradas, S. Parascandola, B. Sealy, R. Grötzschel, U. Kreissig, Nucl. Instr. and Meth. B161-163 (2000) 308.

193 J. Padayachee, K.A. Meyer, V.M. Prozesky, Nucl. Instr. and Meth. B181 (2001) 122. 
${ }^{194}$ P. Neumaier, G. Dollinger, A. Bergmaier, I. Genchev, L. Görgens, R. Fischer, C. Ronning, H. Hofsäss, Nucl. Instr. and Meth. B183 (2001) 48.

195 Workshop on intercomparison and evaluation of software for accelerator-based nuclear techniques of analysis, 28 September - 1 October 2004, Vienna, Austria, IAEA Working Material IAEA-04ME06403.

${ }^{196}$ J.F. Janni, Atomic Data and Nuclear Data Tables 27 (1982) 147.

${ }^{197}$ H. Andersen and J.F. Ziegler, The stopping and ranges of ions in matter, Vol. 3, Pergamon press, New York, 1977.

198 J.F. Ziegler and W.K. Chu, At. Data Nucl. Data Tables 13 (1974) 463.

${ }^{199}$ E. Rauhala in Handbook of Modern Ion Beam Materials Analysis, edited by JR Tesmer and M. Nastasi (Materials Research Society, Pittsburgh, 1995).

${ }^{200}$ H. Jensen, Z. Phys. 77 (1932) 722.

${ }^{201}$ G. Konac, S. Kalbitzer, Ch. Klatt, D. Niemann and R. Stoll, Nucl. Instr. and Meth. B136138 (1998) 159.

${ }^{202}$ E. Huttel, W. Arnold, H. Baumgart and G. Clausnitzer, Nucl. Instr. and Meth. B12 (1985) 193.

${ }^{203}$ J. Lindhard and M. Scharff, Mat. Fys. Medd. Dan. Vid. Selsk. 27(15) (1953). 
